\title{
From contraction to gene expression: nanojunctions of the sarco/endoplasmic reticulum deliver site- and function-specific calcium signals
}

\author{
A. Mark Evans ${ }^{1 *}$, Nicola Fameli ${ }^{2}$, Oluseye A. Ogunbayo ${ }^{1}$, Jingxian Duan $^{1} \&$ \\ Jorge Navarro-Dorado ${ }^{1}$ \\ ${ }^{1}$ Centre for Integrative Physiology, College of Medicine and Veterinary Medicine, Hugh Robson Building, University of Edinburgh, \\ Edinburgh EH8 9XD, UK; \\ ${ }^{2}$ Institute of Biophysics, Medical University of Graz, Graz,8010, Austria
}

Received March 5, 2015; accepted April 7, 2016; published online June 29, 2016

\begin{abstract}
Calcium signals determine, for example, smooth muscle contraction and changes in gene expression. How calcium signals select for these processes is enigmatic. We build on the "panjunctional sarcoplasmic reticulum" hypothesis, describing our view that different calcium pumps and release channels, with different kinetics and affinities for calcium, are strategically positioned within nanojunctions of the SR and help demarcate their respective cytoplasmic nanodomains. SERCA2b and RyR1 are preferentially targeted to the sarcoplasmic reticulum (SR) proximal to the plasma membrane (PM), i.e., to the superficial buffer barrier formed by PM-SR nanojunctions, and support vasodilation. In marked contrast, SERCA2a may be entirely restricted to the deep, perinuclear SR and may supply calcium to this sub-compartment in support of vasoconstriction. RyR3 is also preferentially targeted to the perinuclear SR, where its clusters associate with lysosome-SR nanojunctions. The distribution of RyR2 is more widespread and extends from this region to the wider cell. Therefore, perinuclear RyR3s most likely support the initiation of global calcium waves at L-SR junctions, which subsequently propagate by calcium-induced calcium release via RyR2 in order to elicit contraction. Data also suggest that unique SERCA and RyR are preferentially targeted to invaginations of the nuclear membrane. Site- and function-specific calcium signals may thus arise to modulate stimulus-response coupling and transcriptional cascades.
\end{abstract}

calcium, nanojunction, ryanodine receptor, sarco/endoplasmic reticulum calcium ATPase, smooth muscle, gene expression, contraction

Citation: Evans, A.M., Fameli, N., Ogunbayo, O.A., Duan, J., and Jorge, N.D. (2016). From contraction to gene expression: nanojunctions of the sarco/endoplasmic reticulum deliver site- and function-specific calcium signals. Sci China Life Sci 59, 749-763. doi: 10.1007/s11427-016-5071-0

\section{INTRODUCTION}

$\mathrm{Ca}^{2+}$ signals govern a wide variety of cell functions, from muscle contraction, exocytosis and cell division to gene expression. Cells must therefore provide for the generation of different $\mathrm{Ca}^{2+}$ signals that select for one or a combination of functions. Given the multiplicity of functional signals we must therefore ask: how can fluctuations in the concentra-

*Corresponding author (email: mark.evans@ed.ac.uk) tion of one ion, $\mathrm{Ca}^{2+}$, exert such selective and multifaceted control? The generally accepted view is that both the spatial and temporal characteristics of $\mathrm{Ca}^{2+}$ transients code for selective modulation of molecular targets and thereby engage appropriate cell and system function.

In all cell types stimulus-response coupling is largely controlled by interactions between voltage-gated $\mathrm{Ca}^{2+}$ channels of the plasma membrane (PM) or its invaginations (T-tubules or caveolae) and $\mathrm{Ca}^{2+}$ release channels in the sarco/endoplasmic reticulum (S/ER). Pharmaco-response 
coupling provides for greater signal diversity, via gating of the 3 known S/ER resident $\mathrm{IP}_{3}$ receptors $\left(\mathrm{IP}_{3} \mathrm{R} 1-3\right)$ by inositol 1,4,5 trisphosphate $\left(\mathrm{IP}_{3}\right)$ (Berridge, 2008), modulation of the $3 \mathrm{~S} / \mathrm{ER}$ resident ryanodine receptors subtypes (RyR1-3) by $\mathrm{Ca}^{2+}$ and/or cyclic adenosine diphosphateribose (cADPR) (Evans et al., 2005b; Lee, 2004; Morgan and Galione, 2008), and by the gating of the endolysosome targeted two pore channels (TPC1-3). Clearly, therefore, the spatiotemporal pattern of $\mathrm{Ca}^{2+}$ signals will be governed by those $\mathrm{Ca}^{2+}$ mobilising messenger(s) recruited by a given stimulus, the $\mathrm{Ca}^{2+}$ release channels expressed by a given cell and the consequential selection by these messengers of $\mathrm{Ca}^{2+}$ release from designate intracellular $\mathrm{Ca}^{2+}$ stores (Churchill et al., 2002; Kinnear et al., 2004; Yamasaki et al., 2004). However, while there is a degree of flexibility within the identified signalling pathways described thus far, the current model still appears to be too simplistic to allow for the appropriate governance of all known $\mathrm{Ca}^{2+}$-dependent processes from, for example, gene expression, autophagy and cell proliferation to contraction and programmed cell death.

The present article will focus on the growing body of evidence in support of the view that the functional specification of $\mathrm{Ca}^{2+}$ signals is determined by the targeting of $\mathrm{Ca}^{2+}$ release channels and transporters to junctional complexes formed by membrane-membrane pairs that are less than $30 \mathrm{~nm}$ apart in all relevant cases reported to date. The specified distance of separation alone designates these complexes as nanojunctions (NOT MICRODOMAINS!) which have now been shown to exist between the S/ER and the plasma membrane (PM), lysosomes, mitochondria and the nucleus (van Breemen et al., 2013). The underlying mechanisms of signal generation are likely more elaborate in nature and clearly rely on the strategic spatial positioning within each nanojunction of different types of $\mathrm{Ca}^{2+}$ transporters and release channels, each of which may be characterized by different kinetics and affinities for $\mathrm{Ca}^{2+}$ (Clark et al., 2010).

\section{WHAT ARE NANOJUNCTIONS?}

Perhaps the first nanojunction ever described in terms of its functional importance was an intercellular junction, namely the neuromuscular junction. Here the pre- and postjunctional membranes are approximately $20 \mathrm{~nm}$ apart and extend roughly parallel to each other for several hundred $\mathrm{nm}$. There is no doubt as to the importance of this nanojunction to our understanding of how the release of acetylcholine coordinates neuromuscular transmission (Del Castillo and Katz, 1956). By comparison, however, little attention has been given to the presence, function and plasticity of nanojunctions between intracellular membranes. Perhaps the one exception is in skeletal and cardiac muscles, where the importance to excitation-contraction coupling of the junctional complexes formed between the T-tubules of the sarcolemma and terminal cisternae of the sarcoplasmic reticulum is well documented. Importantly, in each instance the junctional membrane pair are separated by $\sim 20 \mathrm{~nm}$ or less (FranziniArmstrong, 1964; Ramesh et al., 1998; Rosenbluth, 1962), akin to the neuromuscular junction. In cardiac muscle, sarcolemma-SR nanojunctions are essential to the targeting of $\mathrm{Ca}^{2+}$ influx to those RyRs located on the terminal cisternae of the SR and thus to the coordination of contraction by $\mathrm{Ca}^{2+}$-induced $\mathrm{Ca}^{2+}$ release from the SR. We can therefore define these sarcolemma-SR junctions as the archetypal intracellular nanojunctions that are designed to accurately deliver $\mathrm{Ca}^{2+}$ to a defined target, RyR2, above all else. Although junctional complexes are formed between other organelles, we will concentrate on how the main $\mathrm{Ca}^{2+}$ regulatory organelle, the sarco/endoplasmic reticulum (S/ER), generates highly localized $\mathrm{Ca}^{2+}$ signals to select for different functions. It is now our view that all active nanojunctions constitute two biological membranes that are separated by a highly structured cytoplasmic space 10 to $50 \mathrm{~nm}$ in width, typically a few $100 \mathrm{~nm}$ in extension and that, at each side, the membrane pair contain complementary ion transporters and channels for delivery and/or receipt of specified $\mathrm{Ca}^{2+}$ signals. As described previously, we predict that both the ultra-structure and electrostatic properties of the nanojunction together with the composition of transport molecules embedded in their limiting membranes ensure that cytoplasmic cation concentrations, $\mathrm{Ca}^{2+}$ in particular, are locally determined. $\mathrm{Ca}^{2+}$ may thus target "receptive sites" of different affinities and modulate function appropriately. Furthermore, we envisage that intracellular nanojunctions of the S/ER are widespread across all cell types and that they underpin the selective regulation of functions as diverse as muscle contraction, gene expression and cell division (van Breemen et al., 2013).

\section{THE PANJUNCTIONAL SARCOPLASMIC RETICULUM HYPOTHESIS}

The first convincing evidence of nanojunctions within smooth muscle came from electron micrographs that revealed narrow gaps of $\sim 20 \mathrm{~nm}$ between the peripheral or superficial SR and the PM (Devine et al., 1972; Gabella, 1971). Once more, it is notable that the distance separating the junctional membrane pair is of the order of $20 \mathrm{~nm}$. That these junctions were of functional importance was demonstrated by van Breemen, who showed that peripheral cytoplasmic domains between the PM and peripheral SR are characterized by restricted diffusion (Van Breemen, 1977). In brief, it was concluded that once $\mathrm{Ca}^{2+}$ enters this nanospace, it is either pumped into the SR or diffuses into the bulk myoplasm. Surprisingly, the concept that site- and function-specific $\mathrm{Ca}^{2+}$ signals may be supported by nanojunctions received little attention thereafter, despite the general acceptance of the importance to neurotransmitter function of the neuromuscular junction and other "synapses". Perhaps this is because conceptually there is little need 
for considerations on junctional signalling beyond a passing nod in the direction of membrane "contact sites", "microdomains" and vague considerations on the passive transfer of ions between organelles, and, let's face it, a lack of understanding of what defining, quantifiable characteristics a true nanojunction confers. A model was therefore proposed which describes the evidence in support of a "Pan-Junctional SR" which incorporates identified nanojunctions between the SR and the PM, mitochondria, lysosomes and the nucleus, each performing separate, but coordinated functions (van Breemen et al., 2013). The most abundant PM-SR junctions appear to selectively regulate luminal $\left[\mathrm{Ca}^{2+}\right]_{\mathrm{SR}}$, hyperpolarization and relaxation, depolarization and vasomotion. These aside, mitochondria-SR junctions regulate mitochondrial energy metabolism, lipid transport, apoptosis and $\mathrm{SR} \mathrm{Ca}{ }^{2+}$ loading (Rowland and Voeltz, 2012) and lysosome-SR junctions underpin evoked calcium-induced calcium release (CICR) from the S/ER which may in turn modulate, for example, contraction, autophagy and cholesterol metabolism (Fameli et al., 2014; Zhu et al., 2010).

Due to the fact that their size alone renders nanojunctions beyond the resolution of current live cell experimentation, their importance to the coordination of ion exchange was first truly visualised by 3-D models of $\mathrm{Ca}^{2+}$ flux across the PM-SR junction of smooth muscles. These models incorporated dimensionally realistic intracellular architecture, transporter kinetics and density, and outcomes suggested that increases of one single $\mathrm{Ca}^{2+}$ ion may raise the local concentration from nanomolar to micromolar; i.e., considerations on bulk concentration may become irrelevant. Despite the fact that these models only accounted for the stochastic element of diffusion, they also highlighted that the functional integrity of PM-SR junctions relies heavily on the close apposition of the two membranes, since various interrogations of these models demonstrated that a separation of less than $50 \mathrm{~nm}$ adequately provided for compartmentalised $\mathrm{Ca}^{2+}$ signalling, and that junctional integrity was lost when the separation of PM and the junctional SR was raised above $50 \mathrm{~nm}$ (Fameli et al., 2007). These studies apart, it could be argued that there is perhaps a lack of additional defining and quantifiable characteristics to extrapolate this argument across the cell. However, we would counter this position by stating that our studies on pulmonary arterial smooth muscle have provided quantitative evidence in support of a requirement for junctional signalling beyond that originally envisaged at the superficial buffer barrier created by PM-SR nanojunctions. In order to develop this hypothesis further, we will therefore focus on the putative cellular nanojunctions of pulmonary arterial myocytes, with reference to other cell types for comparison.

\section{PULMONARY ARTERY DILATION MAY BE MEDIATED BY CADPR-DEPENDENT ACTIVATION OF RYANODINE RECEPTORS}

Our journey towards a realisation of the importance of nanojunctions began with the simple assessment of changes in cytoplasmic $\mathrm{Ca}^{2+}$ concentration upon intracellular dialysis of cADPR from a patch-pipette. High concentrations of cADPR $\left(100 \mu \mathrm{mol} \mathrm{L}{ }^{-1}\right)$ induced global increases in intracellular $\mathrm{Ca}^{2+}$ concentration (Evans, unpublished). However, relatively low concentrations $\left(20 \mu \mathrm{mol} \mathrm{L}^{-1}\right)$ only increased cytoplasmic $\mathrm{Ca}^{2+}$ concentration at the perimeter of the cell and elicited a concomitant membrane hyperpolarisation (Boittin et al., 2003). The hyperpolarisation was reversed by the highly selective $\mathrm{BK}_{\mathrm{Ca}}$ channel antagonist iberiotoxin, by chelating intracellular $\mathrm{Ca}^{2+}$ with BAPTA, by selective block of RyRs with ryanodine and by "depletion" of SR stores by blocking SERCA with cyclopiazonic acid. Most importantly, hyperpolarisation by cADPR was blocked by two different cADPR antagonists. Given that cADPR synthesis had been shown to be up-regulated in a cAMP- and PKA-dependent manner in cardiac muscle (Higashida et al., 1999), it seemed likely that cADPR could mediate hyperpolarisation by adenylyl cyclase coupled receptors, such as $\beta$-adrenoceptors. Consistent with this proposal and previous studies on smooth muscle from a variety of tissues (for review see (Jaggar et al., 2000)) we found that isoprenaline and cAMP induced hyperpolarisation in isolated pulmonary arterial myocytes, and demonstrated that in each case hyperpolarisation exhibited similar pharmacology to hyperpolarisation by cADPR (Boittin et al., 2003). Strikingly, however, the selective PKA antagonist H89 blocked hyperpolarisation by both isoprenaline and cAMP, but was without effect on hyperpolarisation by cADPR. It would appear, therefore, that CADPR is a downstream element in this signalling cascade. Further support for this proposal was derived from studies on isolated pulmonary artery rings without endothelium; vasodilation evoked in response to $\beta$-adrenoceptor activation by isoprenaline was inhibited $(\sim 50 \%)$ by blocking cADPR with the membrane permeable antagonist 8-bromo-cADPR, RyRs with ryanodine and, consistent with the hyperpolarization, by blocking SERCA pumps by pre-incubation with cyclopiazonic acid (Figure 1). We concluded that isoprenaline-induced vasodilation of pulmonary arteries was, in part, evoked by cADPR-dependent activation of RyRs on a cyclopiazonic acid-sensitive SR store,

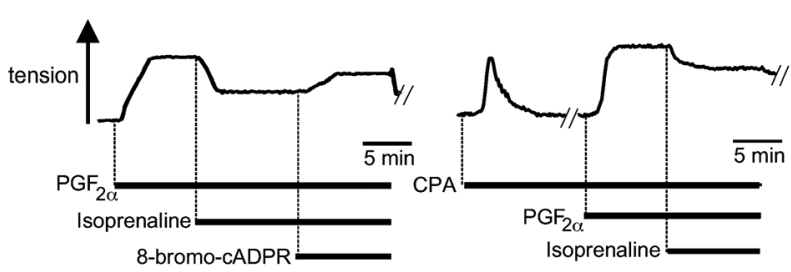

Figure 1 Cyclic ADP-ribose mediates vasodilation by releasing calcium from a cyclopiazonic acid-sensitive sarcoplasmic reticulum store. Vasodilation by isoprenaline $\left(100 \mathrm{nmol} \mathrm{L}^{-1}\right)$ of a pulmonary artery ring, without endothelium, following preconstriction with prostaglandin-F2 $\alpha$ (PGF2 $\alpha$, $50 \mu \mathrm{mol} \mathrm{L}{ }^{-1}$ ) and the effect of (left hand panel) 8-bromo-cADPR (300 $\mu \mathrm{mol} \mathrm{L^{-1 }}$ ) and (right hand panel) preincubation (20 min) with cyclopiazonic acid (CPA, $10 \mu \mathrm{mol} \mathrm{L}{ }^{-1}$ ). 
and the subsequent activation of $\mathrm{BK}_{\mathrm{Ca}}$ upon the mobilisation of $\mathrm{Ca}^{2+}$ from this store (Boittin et al., 2003). This seemed quite consistent with the view that activation of $\mathrm{BK}_{\mathrm{Ca}}$ channels resulted from the induction of highly localised (i.e. non-propagating) cADPR-dependent $\mathrm{Ca}^{2+}$ sparks. In short, at first sight outcomes did not appear to require considerations on junctional coupling between the PM and the SR. Our position was, however, altered by observations in relation to pulmonary artery constriction in response to hypoxia.

\section{REGULATION BY HYPOXIA OF CALCIUM MOBILISATION FROM SARCOPLASMIC RETICULUM IN PULMONARY ARTERIAL SMOOTH MUSCLE}

Before we can elaborate further we must describe the mechanisms that underpin hypoxic pulmonary vasoconstriction (HPV), the defining characteristic by which pulmonary arteries contribute to ventilation-perfusion matching at the lung; systemic arteries dilate in response to hypoxia.

In isolated pulmonary arteries, HPV is biphasic when induced by switching from normoxic to hypoxic gas mixtures (Figure 2), an initial transient constriction (Phase 1) being followed by a slow tonic constriction (Phase 2) (Dipp et al., 2001; Robertson et al., 1995). Both phases of constriction are superimposed upon each other, i.e., they are discrete events that are initiated immediately upon exposure to hypoxia. The initial transient constriction peaks within 5-10 min of the hypoxic challenge, whilst the underlying, tonic constriction peaks after 30-40 min. When the endothelium is removed the gradual amplification of Phase 2, which is driven by the release of an endothelium-derived vasoconstrictor, is not observed and the Phase 1 constriction now declines to a maintained plateau (Figure 2) (Dipp et al., 2001). Continued smooth muscle SR $\mathrm{Ca}^{2+}$ release via RyRs is required for both the induction (Phases 1 and 2) and maintenance (Phase 2) of HPV in isolated pulmonary arteries both with and without endothelium (Dipp et al., 2001). This is evident from the fact that: (i) HPV is abolished following block of $\mathrm{SR} \mathrm{Ca}^{2+}$ release via RyRs, whilst constriction in response to membrane depolarisation $\left(80 \mathrm{mmol} \mathrm{L}^{-1}\right.$ $\mathrm{K}^{+}$) and consequent voltage-gated $\mathrm{Ca}^{2+}$ influx remains unaffected; (ii) HPV persists after removal of extracellular $\mathrm{Ca}^{2+}$, despite the fact that constriction induced by depolarisation is abolished. Maintained constriction of pulmonary artery rings is, however, attenuated by up to $50 \%$ in $\mathrm{Ca}^{2+}$ free medium (Evans et al., 2005a), consistent with the view that HPV is supported by consequent activation of storedepletion activated $\mathrm{Ca}^{2+}$ entry (Weigand et al., 2005). Clearly, therefore, HPV within an intact artery is triggered by the mobilization during hypoxia of $\mathrm{SR} \mathrm{Ca}^{2+}$ stores via RyRs and in manner determined by mechanisms intrinsic to pulmonary arterial myocytes. However experimental out-

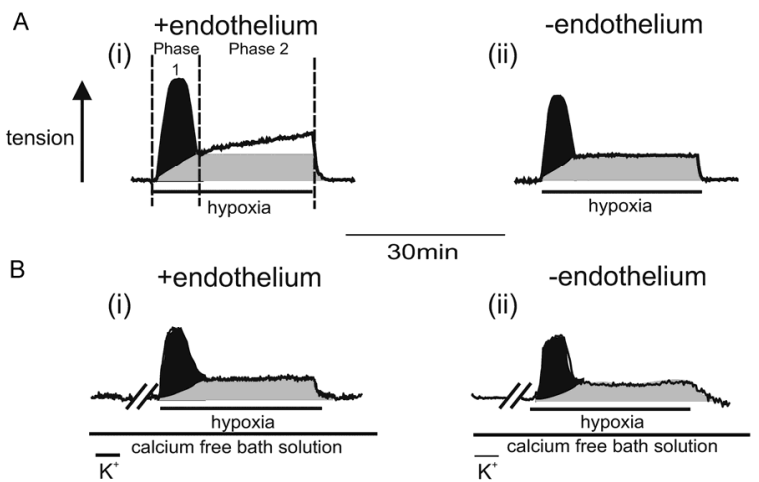

Figure 2 Hypoxic pulmonary vasoconstriction is mediated by intracellular calcium release in pulmonary arterial smooth muscles. A(i), record indicating Phase 1 and Phase 2 of the response of an intact pulmonary artery ring to hypoxia, with the three identified components of HPV: cADPR-independent SR calcium release (black) cADPR-dependent SR calcium release (grey) and endothelium-dependent constriction (white). A(ii), constriction by hypoxia of a pulmonary artery ring without endothelium. B(i), constriction by hypoxia of an intact pulmonary artery ring in the absence of extracellular calcium. B(ii), constriction by hypoxia of a pulmonary artery ring without endothelium in the absence of extracellular calcium.

comes revealed a picture that was yet more complex.

The first truly unexpected observation was that cyclopiazonic acid blocked the Phase 1 constriction but had no effect on Phase 2 (Figure 3) (Dipp and Evans, 2001), despite the fact that both phases of HPV were entirely dependent on the mobilisation of $\mathrm{Ca}^{2+}$ from the SR. This presented us with a further paradox, however, given that our data already suggested that $\mathrm{SR} \mathrm{Ca}^{2+}$ release via RyRs underpinned vasodilation consequent to $\beta$-adrenoceptor activation and also underpinned both phases of HPV (Dipp et al., 2001). More curious still, the effect on HPV of pre-incubating arteries with cyclopiazonic acid was precisely the reverse of outcomes following pre-incubation of arteries with 8-bromo-cADPR, which abolished Phase 2 of HPV without affecting Phase 1 (Figure 2) (Dipp and Evans, 2001). At the time we concluded that Phase 1 might be mediated by the mobilization of an SR compartment served by a cyclopiazonic acid-sensitive SERCA that is inhibited by hypoxia due to a fall in ATP supply, i.e., a reduction in sequestration by this pump might facilitate evoked $\mathrm{SR} \mathrm{Ca}^{2+}$ release. To allow for this and a second phase of constriction driven by maintained cADPR-dependent $\mathrm{SR} \mathrm{Ca}^{2+}$ release, we suggested that one would require the presence of a second, spatially segregated $\mathrm{SR} \mathrm{Ca}^{2+}$ store that is served by a different, cyclopiazonic acid-insensitive SERCA pump (Dipp and Evans, 2001; Evans et al., 2005b).

Although these findings provided our first evidence of functionally segregated SR stores and allowed for further interrogation of our anomalous findings, they presented us with a further paradox. Our data suggested that cADPRdependent SR $\mathrm{Ca}^{2+}$ release via RyRs mediates both vasodilation and vasoconstriction of pulmonary arteries, and in a 


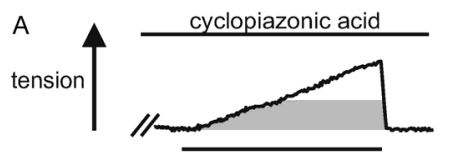

hypoxia $40 \min$

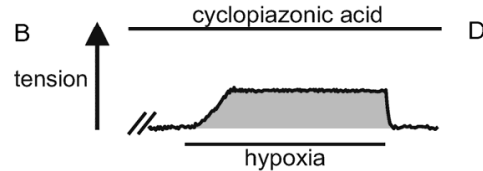

Figure 3 Pharmacologically distinct components of smooth muscle sarcoplasmic reticulum calcium release underpin hypoxic pulmonary vasoconstriction. Constriction by hypoxia (16-21 Torr) of a pulmonary artery ring: (A) with and (B) without endothelium following preincubation (20 min) with cyclopiazonic acid $\left(10 \mu \mathrm{mol} \mathrm{L}^{-1}\right)$; (C) with and (D) without endothelium following preincubation $(20 \mathrm{~min})$ with 8 -bromo-cADPR (300 $\left.\mu \mathrm{mol} \mathrm{L}^{-1}\right)$.

stimulus-specific manner. We concluded that this could only be explained if $\beta$-adrenoceptor signalling targets PKA-dependent cADPR synthesis to RyRs of the "peripheral" SR that is in close apposition to $\mathrm{BK}_{\mathrm{Ca}}$ channels in the plasma membrane (i.e., to PM-SR junctions), whilst cADPR-dependent vasoconstriction results from the activation of a discrete subpopulation of RyRs localized in the "central" SR. Clearly, our data suggested that these discrete SR compartments would have to be served by different SERCA pumps. More precisely, evidence pointed to the possibility that one peripheral SR compartment in close apposition to the plasma membrane would be served by a SERCA pump that is sensitive to cyclopiazonic acid and, by contrast, a second, central SR compartment might be in close apposition to the contractile apparatus and be served by a SERCA pump that is insensitive to cyclopiazonic acid (Boittin et al., 2003; Evans et al., 2005b). This conclusion gained further support from our finding that both SR $\mathrm{Ca}^{2+}$ release in response to hypoxia (Dipp et al., 2001; Salvaterra and Goldman, 1993) and HPV are abolished following SR store depletion by block of SERCA with thapsigargin (Evans, unpublished). In complete agreement with our proposal, previous studies on smooth muscle, the pulmonary vasculature included, have provided evidence of discrete SR compartments (Ethier et al., 2001; Golovina and Blaustein, 1997; Iino et al., 1988; Janiak et al., 2001; Tribe et al., 1994; Yamaguchi et al., 1995). Most significantly, some of these studies shared one common piece of evidence, that the SERCA pump antagonist cyclopiazonic acid selectively depleted one of at least two functionally segregated SR compartments. We therefore sought to determine whether or not multiple SERCA were expressed in pulmonary arterial smooth muscle and, if so, their respective spatial distribution.

\section{SERCA2A AND SERCA2B SERVE DISCRETE SR COMPARTMENTS IN PULMONARY ARTERIAL SMOOTH MUSCLE}

In agreement with previous studies on vascular smooth muscle (Eggermont et al., 1990), we found that SERCA2a and SERCA2b are functionally expressed in pulmonary arterial smooth muscle. Most importantly we identified striking differences in the spatial organization of each of these pumps by visual and semi-quantitative analysis; the distribution by density of labelling for each SERCA isoform within the subplasmalemmal (within $1 \mu \mathrm{m}$ of the plasma membrane) the perinuclear (within $1.5 \mu \mathrm{m}$ of the nucleus) and the extraperinuclear (remainder of the cell) volumes (Clark et al., 2010). The vast majority of SERCA2b labelling, $\sim 70 \%$, lay within the subplasmalemmal region, with only $\sim 8 \%$ and $\sim 20 \%$ of labelling present in the extraperinuclear and perinuclear regions, respectively (Figure 4). In marked contrast, SERCA2a labelling was almost entirely $(\sim 90 \%)$ restricted to the perinuclear region of pulmonary arterial smooth muscle cells (Figure 4). These data suggest, therefore, that native SERCA2b may be sensitive to cyclopiazonic acid and supply an SR compartment that sits proximal to the plasma membrane and underpins $\mathrm{Ca}^{2+}$-dependent vasodilation via adenylyl cyclase coupled receptors, while SERCA2a may supply the putative central SR compartment and represent a cyclopiazonic acidinsensitive, thapsigargin-sensitive SERCA that underpins pulmonary artery constriction by hypoxia.

In this respect it was intriguing to note that SERCA2a and SERCA2b exhibit distinct kinetics. SERCA2b, which may serve PM-SR junctions, has a higher affinity for $\mathrm{Ca}^{2+}$ but lower $V_{\max }$ than the more centrally located SERCA2a (Verboomen et al., 1992). SERCA2b may therefore be dominant under quiescent conditions and function to maintain low levels of cytoplasmic $\mathrm{Ca}^{2+}$ in the vicinity of the

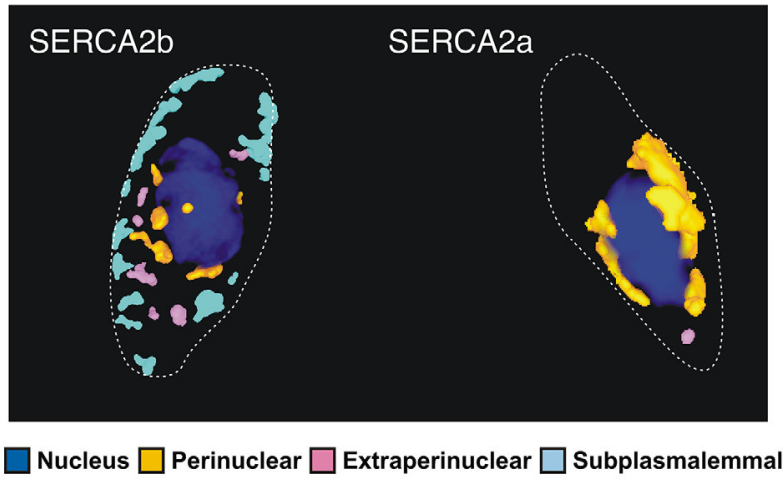

Figure 4 SERCA2a and SERCA2b are differentially distributed within isolated pulmonary arterial smooth muscle cells and may serve functionally segregated SR calcium stores. 3-D reconstruction of deconvolved Z-stacks of images showing the distribution of individual volumes of SERCA2b (left hand panel) and SERCA2a labelling (right hand panel) coloured to indicate distribution by defined regions of the cell; the perinuclear volume, extra-perinuclear volume and sub-plasmalemmal volume. 
contractile apparatus. However, its low $V_{\max }$ may lead to its saturation upon release of $\mathrm{Ca}^{2+}$ from the bulk SR during a phase of contraction. This would allow the cytoplasmic $\mathrm{Ca}^{2+}$ concentration to rise in the vicinity of the contractile apparatus, until such time as vasodilation is promoted by adenylyl cyclase coupled receptors that may: (i) increase the $V_{\max }$ of SERCA2b by PKA-dependent phosphorylation and facilitate the removal of $\mathrm{Ca}^{2+}$ from the greater cytoplasm; (ii) trigger PKA-dependent $\mathrm{Ca}^{2+}$ release from the peripheral $\mathrm{SR}$, leading to plasma membrane hyperpolarization and secondary facilitation of $\mathrm{Ca}^{2+}$ sequestration from the junctional space between the SR and the plasma membrane via the $\mathrm{Na}^{+} / \mathrm{Ca}^{2+}$ exchanger and/or plasma membrane $\mathrm{Ca}^{2+}$ ATPase; importantly this has a physiological precedent in that it mirrors the relationship between uptake 1 and uptake 2 at noradrenergic synapses, the relative affinity and $V_{\max }$ of which determines the concentration-dependent selection of pre- and post-junctional catecholamine uptake by these transporters.

These findings began to square the circle when taken together with our observation that RyR 1 is primarily targeted to the subplasmalemmal region of the pulmonary arterial myocytes (Kinnear et al., 2008), because considerations on the kinetics of RyR1 regulation by $\mathrm{Ca}^{2+}$ were equally revealing. RyR1 exhibits relatively little gain in Po (0-0.2) with increasing cytoplasmic $\mathrm{Ca}^{2+}$ concentration, and inactivates within the $\mu \mathrm{mol} \mathrm{L}^{-1}$ range with full inactivation achieved by $1 \mathrm{mmol} \mathrm{L}^{-1}$ cytoplasmic $\mathrm{Ca}^{2+}$; this may, in part, explain the low gain in Po for RyR1 in response to activation by $\mathrm{Ca}^{2+}$. Due to these facts RyR1 likely provides limited support for signal propagation by CICR (Yang et al., 2001). When allied to the high affinity of SERCA2b for $\mathrm{Ca}^{2+}$ and their respective targeting to PM-SR junctions, the properties of pump and release channel may therefore aid the functional segregation of PM-SR junctions from the bulk cytoplasm. Furthermore it is now apparent that of the available RyRs, RyR1 is most sensitive to activation by cADPR (Ogunbayo et al., 2011); as investigations on vasodilation consequent to $\beta$-adrenoceptor activation had predicted the RyR resident within PM-SR junctions might be.

\section{ARE PM-SR JUNCTIONS POLYMODAL?}

It is possible that PM-SR junction may, given the above, be polymodal. This is clear from the fact that the SR retains the capacity to not only empty when overloaded with $\mathrm{Ca}^{2+}$ (Nazer and van Breemen, 1998a) or signaled to do so by vasodilators (Boittin et al., 2003) but to reload its $\mathrm{Ca}^{2+}$ store once depleted. In short, in order to support continued $\mathrm{Ca}^{2+}$ release into the cytoplasm, the $\mathrm{S} / \mathrm{ER}$ must be replenished by $\mathrm{Ca}^{2+}$ influx from the extracellular fluid, i.e., via storedepletion activated $\mathrm{Ca}^{2+}$ entry pathways (Ginsborg et al., 1980a, b; Putney, 1986). Although we have not studied the mechanisms involved in any detail, our findings are entirely consistent with the view that HPV is supported, but not ini- tiated or maintained, by such store-depletion-activated calcium entry in pulmonary arterial myocytes (Dipp et al., 2001; Evans et al., 2005a).

Refilling of the SR of smooth muscles is accomplished, in part, via PM-SR junctions, which facilitate $\mathrm{Ca}^{2+}$ flux from the extracellular space into the SR via SERCA during activating waves of $\mathrm{SR} \mathrm{Ca}^{2+}$ release (Lee et al., 2001). As in all cell types, a variety of mechanisms support SR refilling during stimulated $\mathrm{Ca}^{2+}$ release. Receptor-operated cation channels, such as the transient receptor potential channel TRPC6, may deliver $\mathrm{Na}^{+}$to the junctional nanospace in a manner that initiates $\mathrm{Ca}^{2+}$ entry via reverse mode $\mathrm{Na}^{+} / \mathrm{Ca}^{2+}$ exchangers (NCX) in the PM, and thus supply $\mathrm{Ca}^{2+}$ to SERCA on the adjacent, junctional SR membranes (Fameli et al., 2007, 2009; Poburko et al., 2007). SR reloading via SERCA may also be facilitated by $\mathrm{Ca}^{2+}$ influx through VGCCs (Takeda et al., 2011), TRPCs (Albert et al., 2009; Rosado et al., 2015; Shi et al., 2016), and the stromal interaction molecule (STIM)/Orai system (Berra-Romani et al., 2008; Soboloff et al., 2012; Takahashi et al., 2007).

All of these mechanisms appear to contribute to SR loading in pulmonary arterial myocytes (Leblanc et al., 2015; Lu et al., 2008; Ogawa et al., 2012), although it should be noted that evidence suggests that discrete pathways of receptor-operated $\mathrm{Ca}^{2+}$ influx may be modulated by $\mathrm{IP}_{3}$ (Kato et al., 2013; Snetkov et al., 2006). That aside, the activation of both TRPCs (Weissmann et al., 2006) and STIM/Orai complexes ( $\mathrm{Lu}$ et al., 2009; $\mathrm{Ng}$ et al., 2012) likely contributes to store-operated $\mathrm{Ca}^{2+}$ entry during HPV.

\section{HPV IS DETERMINED BY SR JUNCTIONAL COUPLING AT AN "INTRACELLULAR SYNAPSE"}

As mentioned previously the effects of a cADPR antagonist, 8-bromo-cADPR, on HPV in isolated pulmonary artery rings were quite different from the effects of ryanodine and caffeine. In arteries with and without endothelium, 8bromo-cADPR had no effect on Phase 1 of HPV. However, it abolished Phase 2 in the presence of the endothelium and blocked the maintained constriction observed in arteries without endothelium (Figure 3) (Dipp and Evans, 2001). Therefore, while cADPR-dependent $\mathrm{SR} \mathrm{Ca}^{2+}$ release is required for the initiation and maintenance of Phase 2 of acute HPV in isolated pulmonary artery rings, cADPR is not required to support the majority of $\mathrm{SR} \mathrm{Ca}^{2+}$ release during the Phase 1 constriction.

Surprisingly, however, and against our expectation at the time, when arteries were pre-incubated with the cADPR antagonist 8-bromo-cADPR, Phase 2 of HPV was blocked in an all-or-none manner (Dipp and Evans, 2001). Briefly, following pre-incubation of isolated pulmonary arteries with $1 \mu \mathrm{mol} \mathrm{L} \mathrm{L}^{-1}$ 8-bromo-cADPR HPV remained unaltered (Figure 5), but pre-incubation with $3 \mu \mathrm{mol} \mathrm{L} \mathrm{L}^{-1} 8$-bromo- 


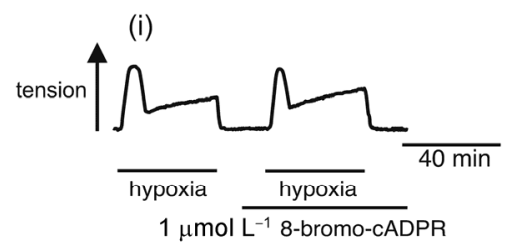

(ii)

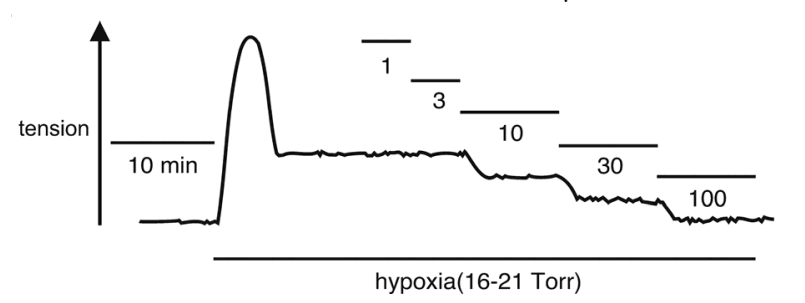

Figure 5 8-bromo-cADPR blocks HPV in an all-or-none manner. Upper panels show that pre-incubating intact pulmonary arteries with 8-bromo-cylic ADP-ribose, a cADPR antagonist, at (i) $1 \mu \mathrm{mol} \mathrm{L}^{-1}$ has no effect but produces all-or-none block of Phase 2 at (ii) $3 \mu \mathrm{mol} \mathrm{L} \mathrm{L}^{-1}$. By contrast, lower panel shows concentration-dependent reversal of maintained HPV by 8-bromo-cylic ADP-ribose in an artery without endothelium.

cADPR abolished the maintained constriction observed during Phase 2. This outcome is incompatible with the block by a competitive antagonist, such as 8-bromocADPR, of a simple process of "agonist-receptor" coupling.

The aforementioned observations were all the more curious given that once initiated the maintained phase of constriction (in pulmonary arteries without endothelium) was reversed by 8 -bromo-cADPR in a concentration-dependent manner and with complete block requiring a concentration of $100 \mu \mathrm{mol} \mathrm{L}{ }^{-1}$ (Dipp and Evans, 2001), approaching 2 orders of magnitude higher than required for all-or-none block following pre-incubation with 8-bromocADPR (Figure 5). Such concentration-dependent reversal of maintained HPV is entirely consistent with the inhibition by a competitive antagonist of "agonist-receptor" coupling at a single population of receptors, quite unlike the all-or-none block observed following pre-incubation with 8-bromo-cADPR.

These findings are reminiscent of the block by $\alpha$-bungarotoxin (or tubocurarine) of transmission at the neuromuscular junction, where inhibition of more than $45 \%$ of skeletal muscle nicotinic acetylcholine receptors blocks neuromuscular transmission in an all-or-none manner (Katz, 1967; Lee et al., 1977). By contrast, following induction of tetanus $\alpha$-bungarotoxin, for example, is less effective and reverses muscle contraction in a concentration-dependent manner (Lee et al., 1977). We concluded that a similar "margin of safety" may also be built into HPV, and suggested that the cADPR-dependent component of HPV may be initiated in an all-or-none manner. In essence, we were considering the possible existence of "junctional RyRs" that could confer all-or-none block of HPV upon pre-incubation with 8-bromo-cADPR, by blocking "activation by cADPR of a certain proportion of RyRs", or by "cADPR-dependent
$\mathrm{Ca}^{2+}$ mobilisation from a subpopulation of RyRs" that are pivotal to the initiation of maintained HPV (Dipp and Evans, 2001; Evans et al., 2005b). All things considered, our view was that HPV was, in part, determined by the initiation of $\mathrm{C} \mathrm{Ca}^{2+}$ signal within an intracellular junction of the SR.

This proposal offers greater complexity than one might imagine, given that RyR subtypes 1, 2 and 3 are highly co-expressed in smooth muscles (Herrmann-Frank et al., 1991; Neylon et al., 1995). Not least because all three RyR subtypes can be expressed in a cADPR-sensitive form and each may exhibit different sensitivities to both $\mathrm{Ca}^{2+}$ and cADPR. In short, the RyR subtype targeted by a given $\mathrm{Ca}^{2+}$ signal could affect markedly the characteristics of any subsequent amplification process.

\section{NAADP INDUCES GLOBAL $\mathrm{Ca}^{2+}$ WAVES AND SMOOTH MUSCLE CONTRACTION VIA LYSOSOME-SR JUNCTIONS}

The junctional complex via which HPV is initiated may have been revealed during subsequent studies on $\mathrm{Ca}^{2+}$ mobilization by nicotinic acid adenine dinucleotide phosphate (NAADP). Importantly, these studies suggested that NAADP initiates global $\mathrm{Ca}^{2+}$ waves in an all-or-none manner in pulmonary arterial myocytes, and does so via a two-pool system (Boittin et al., 2002) that incorporates junctional complexes formed between lysosomes and juxtaposed extensions of the SR.

That NAADP may selectively elicit $\mathrm{Ca}^{2+}$ signals from lysosome-related $\mathrm{Ca}^{2+}$ stores in pulmonary arterial myocytes is supported by the fact that selective depletion of acidic $\mathrm{Ca}^{2+}$ stores by bafilomycin $\mathrm{A} 1$, which blocks the vacuolar $\mathrm{H}^{+}$ATPase, abolishes NAADP-dependent $\mathrm{Ca}^{2+}$ signalling without effect on $\mathrm{SR} \mathrm{Ca}{ }^{2+}$ release via either RyRs or $\mathrm{IP}_{3} \mathrm{Rs}$ (Boittin et al., 2002). We subsequently provided evidence, in a variety of cell types, that NAADP-dependent $\mathrm{Ca}^{2+}$ signals are supported by endolysosome targeted TPCs (TPCN1-3, gene name) (Brailoiu et al., 2009, 2010; Cai and Patel, 2010; Calcraft et al., 2009; Ruas et al., 2010; Zhu et al., 2010; Zong et al., 2009); TPC1 was first described by Ishibashi and co-workers although no functional role was identified (Ishibashi et al., 2000). It should be noted, however, that the role of TPCs in endolysosomal $\mathrm{Ca}^{2+}$ signalling remains controversial, on the grounds of ion selectivity and the capacity for TPC channel gating by the $\mathrm{Ca}^{2+}$ mobilizing messenger NAADP (Jha et al., 2014; Morgan and Galione, 2014; Pitt et al., 2010; Ruas et al., 2015; Schieder et al., 2010; Wang et al., 2012). Nevertheless, substantial evidence suggests that NAADP may trigger intracellular $\mathrm{Ca}^{2+}$ release from acidic stores in a manner that may be supported by all three subtypes of vertebrate TPCs. Of these, only the lysosome targeted TPC2 or TPC3 confer the level of L-S/ER coupling necessary for subsequent amplification of $\mathrm{Ca}^{2+}$ 
bursts from acidic stores by CICR from the S/ER (Ogunbayo et al., 2015b), and TPCN3 is absent in primates (including humans) and some rodents (e.g. mouse, rat) (Calcraft et al., 2009). Our preliminary observations on pulmonary arterial myocytes are consistent with this view, in that NAADP-evoked global $\mathrm{Ca}^{2+}$ waves are abolished in myocytes from Tpcn2 knockout mice (Ogunbayo et al., 2015a).

In the context of the present article, however, it is perhaps most significant that depletion of $\mathrm{SR} \mathrm{Ca}^{2+}$ stores by inhibition of the SERCA pump with thapsigargin (not shown) or block of RyRs with ryanodine (Figure 6), revealed spatially restricted bursts of $\mathrm{Ca}^{2+}$ release in response to NAADP that failed to propagate away from their point of initiation in the absence of either SR stores replete in $\mathrm{Ca}^{2+}$ or functional RyRs (Boittin et al., 2002; Kinnear et al., 2004). In short, NAADP initiates global $\mathrm{Ca}^{2+}$ waves in an all-or-none manner by mobilising acidic, lysosome-related $\mathrm{Ca}^{2+}$ stores that subsequently evoke $\mathrm{Ca}^{2+}$-induced $\mathrm{Ca}^{2+}$ release (CICR) from the $\mathrm{SR}$ via RyRs (Kinnear et al., 2004). NAADP-induced $\mathrm{Ca}^{2+}$ bursts must therefore breach a given threshold in order to elicit a global $\mathrm{Ca}^{2+}$ wave by CICR via RyRs on the SR, and in a manner reminiscent of excitation-contraction coupling at the neuromuscular junction.

Intriguingly, intracellular dialysis of $\mathrm{IP}_{3}$ evoked regener-

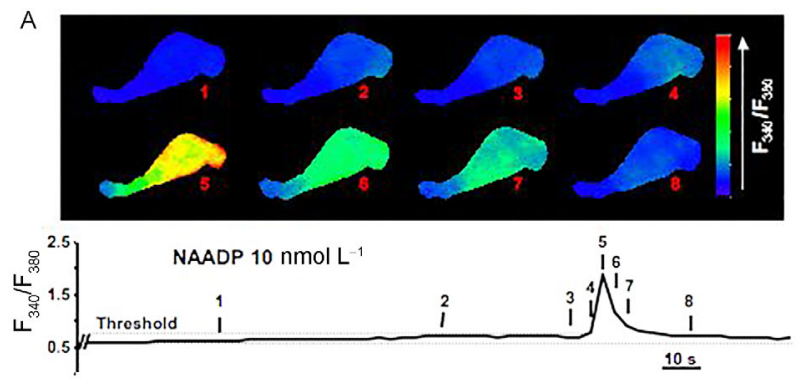

B
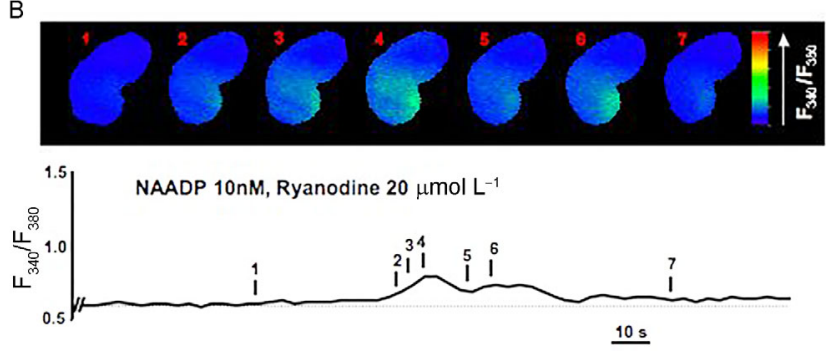

Figure 6 NAADP triggers $\mathrm{Ca}^{2+}$ signals via lysosome-related stores in a manner that leads to subsequent $\mathrm{Ca}^{2+}$-induced $\mathrm{Ca}^{2+}$ release from the sarcoplasmic reticulum via ryanodine receptors in isolated pulmonary arterial myocytes. Upper panels show a series of pseudocolour images of the Fura-2 fluorescence ratio (F340/F380) recorded in a pulmonary artery smooth muscle cell during intracellular dialysis of $10 \mathrm{nmol} \mathrm{L} \mathrm{L}^{-1}$ NAADP, and the Fura-2 fluorescence ratio against time. Lower panels show a series of pseudocolour images and the F340/F380 against time, obtained during the intracellular dialysis of $10 \mathrm{nmol} \mathrm{L}{ }^{-1}$ NAADP after pre-incubation (20 min) of cells with $20 \mu \mathrm{mol} \mathrm{L}{ }^{-1}$ ryanodine. Note that in the absence of functional RyRs, spatially restricted " $\mathrm{Ca}^{2+}$ bursts" are triggered without initiation of a global $\mathrm{Ca}^{2+}$ wave. ative waves that remained unaffected following depletion of acidic stores with bafilomycin or block of RyRs with ryanodine. Moreover the $\mathrm{IP}_{3}$ - but not NAADP-evoked $\mathrm{Ca}^{2+}$ transients were blocked by the $\mathrm{IP}_{3} \mathrm{R}$ antagonist xestospongin C (Boittin et al., 2002). This suggests that in pulmonary arterial myocytes lysosomes couple to the SR by CICR via RyRs but not $\mathrm{IP}_{3} \mathrm{Rs}$, i.e., each may be targeted to different regions of the SR. Indirect support for this view has been provided by the findings of others (Janiak et al., 2001; Subedi et al., 2014).

\section{LYSOSOME-SARCOPLASMIC RETICULUM JUNCTIONS FORM A TRIGGER ZONE FOR CALCIUM SIGNALLING BY NAADP}

Using LysoTracker Red as a fluorescent label for acidic organelles in acutely isolated pulmonary arterial myocytes, we demonstrated that lysosomes form tight perinuclear clusters in a manner consistent with the spatially restricted nature of $\mathrm{Ca}^{2+}$ bursts triggered by NAADP. Importantly, lysosomal clusters were closely associated with a subpopulation of RyRs labelled with Bodipy-Ryanodine (Figure 7) and were separated from these RyRs by a narrow junction, that was well beyond the resolution of deconvolution microscopy $(0.2 \mu \mathrm{m})$ (Kinnear et al., 2004). We proposed, therefore, that lysosomal clusters and RyRs form a highly organised "trigger zone", or intracellular synapse, for $\mathrm{Ca}^{2+}$ signalling by NAADP. The presence of this trigger zone may explain, in part, why $\mathrm{Ca}^{2+}$ bursts by NAADP induce global $\mathrm{Ca}^{2+}$ signals in an all-or-none manner by CICR from the SR via RyRs. This tight coupling of lysosomal $\mathrm{Ca}^{2+}$ stores to a subpopulation of RyRs could also serve to provide the aforementioned "margin of safety" with respect to the initiation of HPV, should lysosome-related $\mathrm{Ca}^{2+}$ release play a role, and confer all-or-none block of HPV by 8-bromo-cADPR due to consequent increases in the threshold for CICR.

We have recently characterised L-SR junctions of rat pulmonary arterial myocytes in greater detail using standard (2D) transmission electron microscopy, and found them to
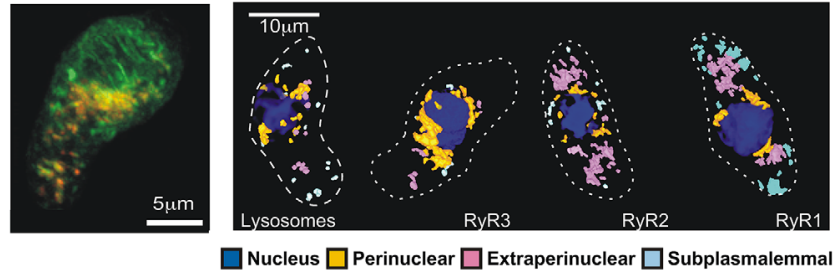

Figure 7 Lysosomes co-localize with ryanodine receptors to form a trigger zone for calcium signalling in response to NAADP. Left hand panel, 3-D reconstruction of a deconvolved Z-stack of images from a pulmonary artery smooth muscle cell showing co-localization (yellow) of lysosomes labelled with LysoTracker Red (red) and ryanodine receptors (RyRs) labelled with Bodipy-Ryanodine (green). Right hand panels, show (from left to right) the distribution relative to the DAPI labelled nucleus of $\alpha$ IGP120, a lysosome-specific marker, and labelling for RyR3, RyR2 and RyR1. 
be a regularly occurring features of these cells. The L-SR widths of pulmonary arterial myocytes, that is the distance between lysosomal and SR membranes, were $\sim 16 \mathrm{~nm}$ and had a lateral extension of $\sim 300 \mathrm{~nm}$ (Fameli et al., 2014). These L-SR junctions are therefore true nanojunctions and exhibit a junctional separation equivalent to the PM-SR junction and, once more, akin to that of the neuromuscular junction. Moreover, assessment of the 3D morphology of L-SR junctions by tomographic transmission electron microscopy showed that some SR segments actually branched out to form narrow cisternae, with a single extension of the SR capable of coupling with multiple organelles. Modeling of this junctional complex has provided strong mechanistic support for our proposals on $\mathrm{Ca}^{2+}$ signaling within L-SR junctions. Firstly, localized $\left[\mathrm{Ca}^{2+}\right]$ transients due to junctional $\mathrm{Ca}^{2+}$ release reach, without fail, values required to breach the threshold for CICR from junctional RyRs (see below). Perhaps most significantly, however, disruption of the nanojunctions decreases the maximum attainable junctional $\left[\mathrm{Ca}^{2+}\right]$ to values below those required for $\mathrm{CICR}$ via RyRs. Consistent with previous studies on the PM-SR junctions, these analyses also predicted a $30-50 \mathrm{~nm}$ functional operating limit for the width of L-SR junctions, above which there is loss of junctional integrity and inadequate control of ion movements within the junctional space. In short, L-SR nanojunctions as reported appear necessary and sufficient for the generation of $\mathrm{Ca}^{2+}$ bursts and their subsequent amplification into propagating, global $\mathrm{Ca}^{2+}$ waves (Fameli et al., 2014).

\section{LYSOSOMES CO-LOCALIZE WITH RYR SUBTYPE 3 TO FORM A TRIGGER ZONE FOR CALCIUM SIGNALLING BY NAADP IN PULMONARY ARTERIAL SMOOTH MUSCLE}

Given that our findings suggested that a subpopulation of RyRs within a junctional complex might underpin HPV and $\mathrm{Ca}^{2+}$ signalling via L-SR junctions, we sought to determine whether or not lysosomes selectively couple to one of the three RyR subtypes expressed in arterial smooth muscle, namely RyR1, RyR2, or RyR3 (Kinnear et al., 2008). As before, the distribution of labelling for a given protein by density was determined for each of three defined regions of the cell relative to the nucleus (defined by DAPI labelling), namely the perinuclear, the sub-plasmalemmal and the extra-perinuclear region. The density of labelling for a specific lysosome marker $(\alpha \operatorname{lgp} 120)$ was $\sim 2$ fold greater in the perinuclear than observed within the extra-perinuclear region and $\sim 4$-fold greater than was observed in the subplasmalemmal region of cells, with dense clusters of labelling evident in the perinuclear region compared to a more diffuse distribution of labelling outside this region. In common with the distribution of lysosomes, RyR3 labelling was concentrated within the perinuclear region of the cell where it was $\sim 4$ and $\sim 14$-fold greater than that in the extra-perinuclear and sub-plasmalemmal regions, respectively. Furthermore, the density of RyR3 labelling within the perinuclear region was $\sim 2$-fold higher than that for either RyR1 or RyR2.

The density of colocalization between lysosomes and each RyR subtype within the perinuclear region of the cell revealed that RyR3 colocalized with $\sim 41 \%$ of the total volume of lysosome labelling, with the density of colocalization being $\sim 4$ - and $\sim 60$-fold greater than that observed in the extra-perinuclear or sub-plasmalemmal regions, respectively. In marked contrast, labelling for RyR2 and RyR1 colocalized with only $13 \%$ and $14 \%$, respectively, of the total volume of lysosome labelling within the perinuclear region and their respective density of colocalization was approximately 2-fold lower than that for RyR3. Furthermore, the mean volume of colocalization between RyR3 and lysosomes was $\sim 2$ fold greater than that for either RyR1 or RyR2. We concluded, therefore, that lysosomal clusters preferentially colocalize with RyR3 in the perinuclear region of the cell to from a trigger zone for $\mathrm{Ca}^{2+}$ signalling at L-SR junctions.

\section{WHY MIGHT RYR3 BE TARGETED TO LYSOSOME-SR JUNCTIONS?}

A determining factor in this respect could be the relative sensitivity of each RyR subtype to CICR, the maximum gain in response to $\mathrm{Ca}^{2+}$ and the relative sensitivity of each receptor subtype to inactivation by $\mathrm{Ca}^{2+}$ (Chen et al., 1997; $\mathrm{Li}$ and Chen, 2001). The threshold for activation of RyR1, RyR2 and RyR3 is similar, with channel activation at cytoplasmic $\mathrm{Ca}^{2+}$ concentrations $>100$ nmol L ${ }^{-1}$. However, estimates of the $\mathrm{EC}_{50}$ are different, with half maximal activation at $>250 \mathrm{nmol} \mathrm{L}^{-1}$ for RyR2 and $>400 \mathrm{nmol} \mathrm{L}^{-1}$ for RyR3. The higher $\mathrm{EC}_{50}$ exhibited by RyR3 could be significant, because this would provide for a higher "margin of safety" with respect to the all-or-none amplification of $\mathrm{Ca}^{2+}$ bursts from lysosomal $\mathrm{Ca}^{2+}$ stores by CICR via RyRs at the lysosome-SR junction, i.e., the probability of false events being initiated would be lower for RyR3 than for RyR2. For the provision of such a margin of safety by RyR3, but not RyR2, our simulations estimate that half maximal SR $\mathrm{Ca}^{2+}$ release via RyR3 would need to occur at an L-SR junctional $\mathrm{Ca}^{2+}$ concentration of $\sim 10 \mu \mathrm{mol} \mathrm{L} \mathrm{L}^{-1}$ (Fameli et al., 2014).

Another factor that may be of significance is that whilst the mean open time versus cytoplasmic $\mathrm{Ca}^{2+}$ concentration for RyR2 and RyR3 are comparable and increase approximately 10 -fold over their activation range, the mean open time for RyR1 is much lower and increases only 2-fold over its activation range. Furthermore, comparison of the Po versus cytoplasmic $\mathrm{Ca}^{2+}$ concentration curves shows that RyR3 (0-1) exhibits a higher gain in Po than does RyR2 
(0-0.9), whilst RyR1 (0-0.2) exhibits relatively little gain in Po with increasing cytoplasmic $\mathrm{Ca}^{2+}$ concentration (Chen et al., 1997; Li and Chen, 2001). Therefore, once the threshold for activation is breached RyR3 would offer greater amplification of $\mathrm{Ca}^{2+}$ bursts from lysosomal $\mathrm{Ca}^{2+}$ stores than would RyR2, whilst amplification via RyR1 would be marginal (see also (Manunta et al., 2000; Yang et al., 2001)). There is also marked variation in the relative sensitivity of each RyR subtype to inactivation by $\mathrm{Ca}^{2+}$. RyR3 exhibits the lowest sensitivity to inactivation by $\mathrm{Ca}^{2+}$ with an $\mathrm{IC}_{50}$ of $3 \mathrm{mmol} \mathrm{L}{ }^{-1}$ whilst that for RyR2 is $2 \mathrm{mmol} \mathrm{L}^{-1}$; in each case channel activity may still be observed at concentrations $>10 \mathrm{mmol} \mathrm{L}^{-1}$ (Chen et al., 1997; Li and Chen, 2001). In marked contrast, RyR1 inactivation occurs within the $\mu \mathrm{mol} \mathrm{L}^{-1}$ range and full inactivation is achieved by $1 \mathrm{mmol} \mathrm{L}{ }^{-1} \mathrm{Ca}^{2+}$. Its sensitivity to inactivation by $\mathrm{Ca}^{2+}$ would therefore render RyR1 unsuitable for a role in the amplification of $\mathrm{Ca}^{2+}$ bursts at lysosome-SR junctions because the local $\mathrm{Ca}^{2+}$ concentration may exceed the threshold for RyR1 inactivation. Therefore, the functional properties of RyR3 make it best suited to a role in the amplification of $\mathrm{Ca}^{2+}$ bursts at lysosome-SR junctions.

\section{HOW MAY $\mathrm{Ca}^{2+}$ SIGNALS PROPAGATE AWAY FROM LYSOSOME-SR JUNCTIONS TO THE WIDER CELL IF RYR3 IS TARGETED TO THE PERINUCLEAR REGION OF CELLS?}

Significantly, the density of RyR3 labelling declines markedly (between 4 -and 14 -fold by region) outside of the perinuclear region of the cell (Kinnear et al., 2008). It seems unlikely, therefore, that RyR3 functions to carry a propagating $\mathrm{Ca}^{2+}$ wave far beyond the point of initiation of CICR within the proposed trigger zone for $\mathrm{Ca}^{2+}$ signalling via L-SR junctions. Given this finding it may be of significance that the density of labelling for RyR 2 increases markedly in the extra-perinuclear region when compared to the perinuclear region and exhibits a $\sim 3$-fold greater density of labelling within this region than observed for either RyR3 or RyR1. This suggests that RyR2, but not RyR1, may function to receive $\mathrm{Ca}^{2+}$ from RyR3 at the interface of the lysosome-SR junction and thereby allow for further propagation of the $\mathrm{Ca}^{2+}$ signal via CICR. Such a role would be supported by the lower $\mathrm{EC}_{50}$ for CICR via RyR2, which would insure that once initiated a propagating $\mathrm{Ca}^{2+}$ wave would be less prone to failure. Furthermore, relative to RyR1, its greater intrinsic gain and lower sensitivity to inactivation by $\mathrm{Ca}^{2+}$ would render RyR2 most suitable to a role in the wider propagation of a global $\mathrm{Ca}^{2+}$ wave.

If clusters of RyR3 do indeed sit within the lysosome-SR junction and an array of RyR2 carries propagating $\mathrm{Ca}^{2+}$ signals away from this junction to trigger HPV, preincubation of pulmonary arteries with 8-bromo-cADPR could block HPV in an all-or-none manner by increasing the threshold for CICR via RyR3 and/or RyR2. Furthermore, once initiated, if regenerative, propagating $\mathrm{Ca}^{2+}$ waves via RyR2 are maintained by an increase in cADPR accumulation in the absence of further $\mathrm{Ca}^{2+}$ release from lysosomerelated stores, 8-bromo-cADPR could reverse associated pulmonary artery constriction in a concentration-dependent manner. In this respect it is important to note that $\mathrm{Ca}^{2+}$ may also sensitise RyRs to activation by cADPR (Panfoli et al., 1999). The combinatorial effects of $\mathrm{Ca}^{2+}$ and cADPR are therefore of fundamental importance (Morgan and Galione, 2008), not least with regard to the threshold for activation of RyRs by either agent. Moreover the threshold for CICR via RyRs may also be modulated by the luminal $\mathrm{Ca}^{2+}$ concentration of the SR (Beard et al., 2002; Ching et al., 2000; Gilchrist et al., 1992; Gyorke and Gyorke, 1998; Tripathy and Meissner, 1996), which could in turn be primed by $\mathrm{Ca}^{2+}$ taken up via SERCA2a during lysosomal $\mathrm{Ca}^{2+}$ bursts that fail to breach the threshold for CICR from the SR.

At this point it may be important to note that even though the $\mathrm{Ca}^{2+}$ signalling domain for contraction may be of a larger scale, its distribution is far from homogeneous. Separate PM regions have been described for filament attachment and caveolae (Moore et al., 2004) and the density of myosin filaments appears to be less in the cell periphery than central myoplasm (Lee et al., 2002). In addition, the functional $\mathrm{Ca}^{2+}$-binding protein calmodulin is tethered to the myofilaments rather than free in solution (Wilson et al., 2002). Therefore, we cannot rule out the capacity for SRmyofilament coupling along the path of propagating $\mathrm{Ca}^{2+}$ waves, with a path length between the SR membrane pairs and calmodulin being on the nanoscale.

\section{IS THERE A FUNCTIONAL REFERENCE POINT FOR THE TWO PHASES OF SR CALCIUM RELEASE DURING HYPOXIA?}

Given that vasodilation in response to activation of adenylyl cyclase coupled receptors and Phase 1 of HPV are inhibited by cyclopiazonic acid, they likely utilise a common SR store. It is possible, therefore, that $\mathrm{SR} \mathrm{Ca}^{2+}$ release by hypoxia serves two purposes. Hypoxia may primarily trigger constriction by cADPR-dependent $\mathrm{Ca}^{2+}$ release from a central SR compartment(s) that is in close apposition to the contractile apparatus and served by a cyclopiazonic acid-insensitive SERCA pump (SERCA2a). A secondary action of hypoxia may be to deplete a peripheral SR compartments, by inhibition of a cyclopiazonic acid-sensitive SERCA pump (SERCA2b), that are in close apposition to the plasma membrane and which normally mediate vasodilation by releasing $\mathrm{Ca}^{2+}$ via RyR1 within PM-SR junctions in order to trigger membrane hyperpolarization and thus facilitate $\mathrm{Ca}^{2+}$ sequestration via plasma membrane $\mathrm{Ca}^{2+}$ ATPases and forward mode activity of $\mathrm{Na}^{+} / \mathrm{Ca}^{2+}$ exchangers. This might explain why pulmonary vasodilation by 
$\beta$-adrenoceptor activation is abolished by hypoxia (McIntyre et al., 1995) and why HPV is enhanced by cyclopiazonic acid (Morio and McMurtry, 2002) but abolished by thapsigargin (Evans unpublished). In this respect it is also intriguing to note that in pulmonary arterial myocytes from patients with pulmonary arterial hypertension a sustained rise in cAMP increases store-operated $\mathrm{Ca}^{2+}$ entry via a PKA-dependent pathway, but inhibits store-operated calcium entry in pulmonary arterial myocytes from normotensive patients (Zhang et al., 2007). When considered together, these data point to a pathological swing in the balance of support for store-emptying towards store-refilling at the PM-SR junctions. Consistent with this view, it has been proposed that the progression of hypoxic and idiopathic pulmonary hypertension may be facilitated by increases in expression of TRPC1, 3, 4 and 6 , and thus enhanced store-operated $\mathrm{Ca}^{2+}$ entry (Liu et al., 2012; Yu et al., 2009; Zhang et al., 2007, 2014). This may also support the switch from contractile to the proliferative and migratory smooth muscle phenotypes that underpins disease progression (Fernandez et al., 2015).

\section{BEYOND THE CONTRACTILE DOMAIN-DO NUCLEAR INVAGINATIONS PROVIDE A NANODOMAIN FOR THE MODULATION OF GENE EXPRESSION?}

The SR is also contiguous with the outer nuclear envelope (Lesh et al., 1998) and its tubular invaginations (Echevarria et al., 2003; Fricker et al., 1997; Gerasimenko et al., 1995). However, despite the pivotal role of $\mathrm{SR} \mathrm{Ca}^{2+}$ release in excitation-transcription coupling and thus phenotypic modulation (Cartin et al., 2000; Gomez et al., 2002; Stevenson et al., 2001; Wamhoff et al., 2006), there have been few detailed investigations on nuclear $\mathrm{Ca}^{2+}$ signalling in native smooth muscles (Wray and Burdyga, 2010). The current consensus (Bootman et al., 2009; Queisser et al., 2011) is that the nuclear envelope and its invaginations provide the surface area necessary for direct entry of $\mathrm{Ca}^{2+}$ into the nucleus via nuclear pores, driven either by $\mathrm{Ca}^{2+}$ influx across the PM or by activation of RyRs (Marius et al., 2006) and $\mathrm{IP}_{3} \mathrm{Rs}$ (Avedanian et al., 2011; Cardenas et al., 2004; Gerasimenko et al., 1995; Hirose et al., 2008) resident in the deep, perinuclear S/ER. However, early investigations on a variety of cell types including arterial smooth muscle showed that the nuclear membrane restricts direct $\mathrm{Ca}^{2+}$ flux into the nucleus (Himpens et al., 1992a, b; Neylon et al., 1990; Wamhoff et al., 2006; Waybill et al., 1991; Williams et al., 1985), raising the possibility that the nuclear membrane independently regulates $\mathrm{Ca}^{2+}$ signalling. Our pilot studies on pulmonary arterial myocytes not only support this view, but have now provided evidence to suggest that RyR1 and a third subtype of SERCA pump, SERCA1, may be preferentially targeted to the outer nuclear membrane
(Evans, 2013; Navarro-Dorado and Evans, 2015). Although the dimensions of nuclear invaginations vary markedly, their radii rarely exceed $200 \mathrm{~nm}$ and many are blind-ended. It is possible, therefore, that nuclear invaginations may incorporate unique pumps and transporters and thus provide nanodomains within which $\mathrm{Ca}^{2+}$ signals may be segregated, and thus contribute to stimulus-transcription coupling (Wamhoff et al., 2006).

\section{SUMMARY}

We should finish with a summary of the properties conferred by the nanojunctions themselves, and do so in the knowledge that all nanojunctions presently defined create a cytoplasmic nanospace between each junctional membrane pair that is approximately $20 \mathrm{~nm}$ across, irrespective of whether we consider the PM-SR junction, L-SR junction, the nuclear invaginations or for that matter the Daddy of them all, the neuromuscular junction. Any curious individual must now recognise the consistency of this argument, so why $\sim 20 \mathrm{~nm}$ ? This separation of junctional membranes ensures that $\mathrm{Ca}^{2+}$ transients within the junctional nanospaces are segregated from those in the bulk myoplasm that determines, in the case of arterial smooth muscle, contractile activity. Several factors contribute to the restriction of $\left[\mathrm{Ca}^{2+}\right]$ transients to nanojunctions: (i) The geometry of the junctions, especially the distance between membranes, appears to control the retention of $\mathrm{Ca}^{2+}$ in the nanospace, as suggested by preliminary models (Fameli et al., 2007, 2014); (ii) The relatively low diffusivity of (free, let alone buffered) cytoplasmic $\mathrm{Ca}^{2+}$ (Allbritton et al., 1992; Kushmerick and Podolsky, 1969), in combination with the restricted junctional geometry, favours $\mathrm{Ca}^{2+}$ buffering by nanojunctions; (iii) The kinetics of $\mathrm{Ca}^{2+}$ pumps in the junctions is another important element, tightly linked to the previous two factors. For example, if, as predicted, SERCA2b is resident within PM-SR junctions of pulmonary arterial smooth muscle, its high affinity for $\mathrm{Ca}^{2+}$ (Verboomen et al., 1992) may provide a barrier to $\mathrm{Ca}^{2+}$ flux between the $\mathrm{PM}$ and the myofilaments and vice versa (Clark et al., 2010); (iv) Protein complexes that span junctions likely provide physical obstacles to ion mobility in the junctions by increasing path tortuosity (Devine et al., 1972; Poburko et al., 2008).

As discussed, the defined properties of a given nanojunction may allow pulmonary arterial myocytes and other cell types to coordinate the delivery of $\mathrm{Ca}^{2+}$ signals in a manner that allows for the selective induction of, for example: (i) vasoconstriction via L-SR junctions; (ii) vasodilation via PM-SR junctions; (iii) gene expression via nuclear invaginations (Figure 8). In each case, however, the view proposed is most likely an oversimplification of the $\mathrm{Ca}^{2+}$ signalling apparatus available to the cell, a point which is articulated by the fact that PM-SR junctions may be polymodal (Boittin et al., 2003; Nazer and Van Breemen, 1998b; 


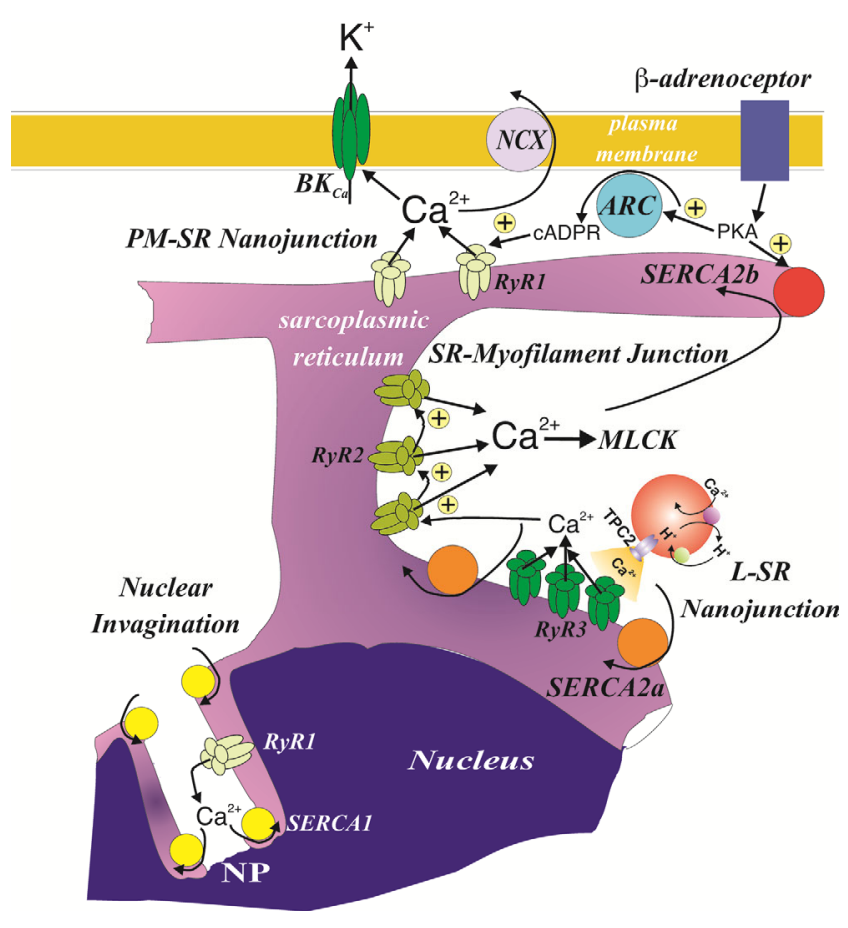

Figure 8 Schematic diagram highlights putative nanojunctions that determine site- and function-specific calcium signals in pulmonary arterial smooth muscle cells. PM, plasma membrane. $\mathrm{BK}_{\mathrm{Ca}}$, large conductance calcium- and voltage-activated potassium current. NCX, sodium/calcium exchanger. SR, sarcoplasmic reticulum. RyR, Ryanodine receptor. SERCA, Sarco/endoplasmic reticulum calcium ATPase. ARC, ADP-ribosyl cylcase. PKA, protein kinase A. cADPR, cyclic adenosine diphosphate-ribose. MLCK, myosin light chain kinase. NP, nuclear pore.

van Breemen et al., 1995). The precise configuration of junctional complexes may therefore be context dependent, and vary not only between cell types but also throughout the path of cell differentiation, during repair and aging. In short, we are likely at the dawn of a true appreciation of the importance of nanojunctions and the complexity and versatility they afford cellular $\mathrm{Ca}^{2+}$ signals.

Compliance and ethics The author(s) declare that they have no conflict of interest.

Acknowledgements This work was supported by the British Heart Foundation (29885).

Albert, A.P., Saleh, S.N., and Large, W.A. (2009). Identification of canonical transient receptor potential (TRPC) channel proteins in native vascular smooth muscle cells. Curr Med Chem 16, 1158-1165.

Allbritton, N.L., Meyer, T., and Stryer, L. (1992). Range of messenger action of calcium ion and inositol 1,4,5-trisphosphate. Science 258, 1812-1815.

Avedanian, L., Jacques, D., and Bkaily, G. (2011). Presence of tubular and reticular structures in the nucleus of human vascular smooth muscle cells. J Mol Cell Cardiol 50, 175-186.

Beard, N.A., Sakowska, M.M., Dulhunty, A.F., and Laver, D.R. (2002). Calsequestrin is an inhibitor of skeletal muscle ryanodine receptor calcium release channels. Biophys J 82, 310-320.

Berra-Romani, R., Mazzocco-Spezzia, A., Pulina, M.V., and Golovina,
V.A. (2008). $\mathrm{Ca}^{2+}$ handling is altered when arterial myocytes progress from a contractile to a proliferative phenotype in culture. Am J Physiol 295, C779-C790.

Berridge, M.J. (2008). Smooth muscle cell calcium activation mechanisms. J Pphysiol 586, 5047-5061.

Boittin, F.X., Dipp, M., Kinnear, N.P., Galione, A., and Evans, A.M. (2003). Vasodilation by the calcium-mobilizing messenger cyclic ADP-ribose. J Biol Chem 278, 9602-9608.

Boittin, F.X., Galione, A., and Evans, A.M. (2002). Nicotinic acid adenine dinucleotide phosphate mediates $\mathrm{Ca}^{2+}$ signals and contraction in arterial smooth muscle via a two-pool mechanism. Circ Res 91, 1168-1175.

Bootman, M.D., Fearnley, C., Smyrnias, I., MacDonald, F., and Roderick, H.L. (2009). An update on nuclear calcium signalling. J Cell Sci 122, 2337-2350.

Brailoiu, E., Churamani, D., Cai, X., Schrlau, M.G., Brailoiu, G.C., Gao, X., Hooper, R., Boulware, M.J., Dun, N.J., Marchant, J.S., and Patel., S. (2009). Essential requirement for two-pore channel 1 in NAADPmediated calcium signaling. J Cell Biol 186, 201-209.

Brailoiu, E., Hooper, R., Cai, X., Brailoiu, G.C., Keebler, M.V., Dun, N.J., Marchant, J.S., and Patel, S. (2010). An ancestral deuterostome family of two-pore channels mediates nicotinic acid adenine dinucleotide phosphate-dependent calcium release from acidic organelles. J Biol Chem 285, 2897-2901.

Cai, X., and Patel, S. (2010). Degeneration of an intracellular ion channel in the primate lineage by relaxation of selective constraints. Mol Biol Evol 27, 2352-2359.

Calcraft, P.J., Ruas, M., Pan, Z., Cheng, X., Arredouani, A., Hao, X., Tang, J., Rietdorf, K., Teboul, L., Chuang, K.T., Lin, P., Xiao, R., Wang, C., Zhu, Y., Lin, Y., Wyatt, C.N., Parrington, J.,Ma, J., Evans, A.M., Galione, A., and Zhu, M.X. (2009). NAADP mobilizes calcium from acidic organelles through two-pore channels. Nature 459, 596-600.

Cardenas, C., Muller, M., Jaimovich, E., Perez, F., Buchuk, D., Quest, A.F., and Carrasco, M.A. (2004). Depolarization of skeletal muscle cells induces phosphorylation of cAMP response element binding protein via calcium and protein kinase Calpha. J Biol Chem 279, 39122-39131.

Cartin, L., Lounsbury, K.M., and Nelson, M.T. (2000). Coupling of $\mathrm{Ca}^{2+}$ to CREB activation and gene expression in intact cerebral arteries from mouse: roles of ryanodine receptors and voltage-dependent $\mathrm{Ca}^{2+}$ channels. Circ Res 86, 760-767.

Chen, S.R., Li, X., Ebisawa, K., and Zhang, L. (1997). Functional characterization of the recombinant type $3 \mathrm{Ca}^{2+}$ release channel (ryanodine receptor) expressed in HEK293 cells. J Biol Chem 272, 24234-24246.

Ching, L.L., Williams, A.J., and Sitsapesan, R. (2000). Evidence for $\mathrm{Ca}^{2+}$ activation and inactivation sites on the luminal side of the cardiac ryanodine receptor complex. Circ Res 87, 201-206.

Churchill, G.C., Okada, Y., Thomas, J.M., Genazzani, A.A., Patel, S., and Galione, A. (2002). NAADP mobilizes $\mathrm{Ca}^{2+}$ from reserve granules, lysosome-related organelles, in sea urchin eggs. Cell 111, 703-708.

Clark, J.H., Kinnear, N.P., Kalujnaiab, S., Cramb, G., Fleischer, S., Jeyakumar, L.H., Wuytack, F., and Evans, A.M. (2010). Identification of functionally segregated sarcoplasmic reticulum calcium stores in pulmonary arterial smooth muscle. J Biol Chem 285, 13542-13549.

Del Castillo, J., and Katz, B. (1956). Localization of active spots within the neuromuscular junction of the frog. J Pphysiol 132, 630-649.

Devine, C.E., Somlyo, A.V., and Somlyo, A.P. (1972). Sarcoplasmic reticulum and excitation-contraction coupling in mammalian smooth muscles. J Cell Biol 52, 690-718.

Dipp, M., and Evans, A.M. (2001). Cyclic ADP-ribose is the primary trigger for hypoxic pulmonary vasoconstriction in the rat lung in situ. Circ Res 89, 77-83.

Dipp, M., Nye, P.C., and Evans, A.M. (2001). Hypoxic release of calcium from the sarcoplasmic reticulum of pulmonary artery smooth muscle. Am J Physiol Lung Cell Mol Physiol 281, L318-L325.

Echevarria, W., Leite, M.F., Guerra, M.T., Zipfel, W.R., and Nathanson, M.H. (2003). Regulation of calcium signals in the nucleus by a nucleoplasmic reticulum. Nat Cell Biol 5, 440-446.

Eggermont, J.A., Wuytack, F., Verbist, J., and Casteels, R. (1990). 
Expression of endoplasmic-reticulum $\mathrm{Ca}^{2+}$-pump isoforms and of phospholamban in pig smooth-muscle tissues. Biochem J 271, 649-653

Ethier, M.F., Yamaguchi, H., and Madison, J.M. (2001). Effects of cyclopiazonic acid on cytosolic calcium in bovine airway smooth muscle cells. Am J Physiol Lung Cell Mol Physiol 281, L126-L133.

Evans, A.M. (2013). From contraction to gene expression: functionspecific calcium signals are delivered by the strategic positioning of calcium pumps and release channels within membrane-membrane nanojunctions of the sarcoplasmic reticulum. In Proceedings of Physiol Soc 37th Congress of IUPS (Birmingham, UK) SA402.

Evans, A.M., Mustard, K.J., Wyatt, C.N., Peers, C., Dipp, M., Kumar, P., Kinnear, N.P., and Hardie, D.G. (2005a). Does AMP-activated protein kinase couple inhibition of mitochondrial oxidative phosphorylation by hypoxia to calcium signaling in $\mathrm{O}_{2}$-sensing cells? J Biol Chem 280, 41504-41511.

Evans, A.M., Wyatt, C.N., Kinnear, N.P., Clark, J.H., and Blanco, E.A. (2005b). Pyridine nucleotides and calcium signalling in arterial smooth muscle: from cell physiology to pharmacology. Pharmacol Ther 107, 286-313.

Fameli, N., Kuo, K.H., and van Breemen, C. (2009). A model for the generation of localized transient $\left[\mathrm{Na}^{+}\right]$elevations in vascular smooth muscle. Biochem Biophys Res Commun 389, 461-465.

Fameli, N., Ogunbayo, O.A., van Breemen, C., and Evans, A.M. (2014). Cytoplasmic nanojunctions between lysosomes and sarcoplasmic reticulum are required for specific calcium signaling. F1000Res 3, 93.

Fameli, N., van Breemen, C., and Kuo, K.H. (2007). A quantitative model for linking $\mathrm{Na}^{+} / \mathrm{Ca}^{2+}$ exchanger to SERCA during refilling of the sarcoplasmic reticulum to sustain $\left[\mathrm{Ca}^{2+}\right]$ oscillations in vascular smooth muscle. Cell Calcium 42, 565-575.

Fernandez, R.A., Wan, J., Song, S., Smith, K.A., Gu, Y., Tauseef, M., Tang, H., Makino, A., Mehta, D., and Yuan, J.X. (2015). Upregulated expression of STIM2, TRPC6, and Orai2 contributes to the transition of pulmonary arterial smooth muscle cells from a contractile to proliferative phenotype. Am J Physiol 308, C581-C593.

Franzini-Armstrong, C. (1964). Fine structure of sarcoplasmic reticulum and tranverse tubular system in muscle fibers. Fed Proc 23, 887-895.

Fricker, M., Hollinshead, M., White, N., and Vaux, D. (1997). Interphase nuclei of many mammalian cell types contain deep, dynamic, tubular membrane-bound invaginations of the nuclear envelope. J Cell Biol 136, 531-544.

Gabella, G. (1971). Caveolae intracellulares and sarcoplasmic reticulum in smooth muscle. J Cell Sci 8, 601-609.

Gerasimenko, O.V., Gerasimenko, J.V., Tepikin, A.V., and Petersen, O.H. (1995). ATP-dependent accumulation and inositol trisphosphate- or cyclic ADP-ribose-mediated release of $\mathrm{Ca}^{2+}$ from the nuclear envelope. Cell 80, 439-444.

Gilchrist, J.S., Belcastro, A.N., and Katz, S. (1992). Intraluminal Ca ${ }^{2+}$ dependence of $\mathrm{Ca}^{2+}$ and ryanodine-mediated regulation of skeletal muscle sarcoplasmic reticulum $\mathrm{Ca}^{2+}$ release. J Biol Chem 267, 20850-20856.

Ginsborg, B.L., House, C.R., and Mitchell, M.R. (1980a). A calcium-readmission response recorded from Nauphoeta salivary gland acinar cells. J Pphysiol 304, 437-447.

Ginsborg, B.L., House, C.R., and Mitchell, M.R. (1980b). On the role of calcium in the electrical responses of cockroach salivary gland cells to dopamine. J Pphysiol 303, 325-335.

Golovina, V.A., and Blaustein, M.P. (1997). Spatially and functionally distinct $\mathrm{Ca}^{2+}$ stores in sarcoplasmic and endoplasmic reticulum. Science 275, 1643-1648.

Gomez, M.F., Stevenson, A.S., Bonev, A.D., Hill-Eubanks, D.C., and Nelson, M.T. (2002). Opposing actions of inositol 1,4,5-trisphosphate and ryanodine receptors on nuclear factor of activated T-cells regulation in smooth muscle. J Biol Chem 277, 37756-37764.

Gyorke, I., and Gyorke, S. (1998). Regulation of the cardiac ryanodine receptor channel by luminal $\mathrm{Ca}^{2+}$ involves luminal $\mathrm{Ca}^{2+}$ sensing sites. Biophys J 75, 2801-2810.

Herrmann-Frank, A., Darling, E., and Meissner, G. (1991). Functional characterization of the $\mathrm{Ca}^{2+}$-gated $\mathrm{Ca}^{2+}$ release channel of vascular smooth muscle sarcoplasmic reticulum. Pflugers Arch 418, 353-359.

Higashida, H., Egorova, A., Higashida, C., Zhong, Z.G., Yokoyama, S., Noda, M., and Zhang, J.S. (1999). Sympathetic potentiation of cyclic ADP-ribose formation in rat cardiac myocytes. J Biol Chem 274, 33348-33354.

Himpens, B., De Smedt, H., and Casteels, R. (1992a). Kinetics of nucleocytoplasmic $\mathrm{Ca}^{2+}$ transients in DDT1 MF-2 smooth muscle cells. Am J Physiol 263, C978-985.

Himpens, B., De Smedt, H., Droogmans, G., and Casteels, R. (1992b). Differences in regulation between nuclear and cytoplasmic $\mathrm{Ca}^{2+}$ in cultured smooth muscle cells. Am J Physiol 263, C95-C105.

Hirose, M., Stuyvers, B., Dun, W., Ter Keurs, H., and Boyden, P.A. (2008). Wide long lasting perinuclear $\mathrm{Ca}^{2+}$ release events generated by an interaction between ryanodine and IP3 receptors in canine Purkinje cells. J Mol Cell Cardiol 45, 176-184.

Iino, M., Kobayashi, T., and Endo, M. (1988). Use of ryanodine for functional removal of the calcium store in smooth muscle cells of the guinea-pig. Biochem Biophys Res Commun 152, 417-422.

Ishibashi, K., Suzuki, M., and Imai, M. (2000). Molecular cloning of a novel form (two-repeat) protein related to voltage-gated sodium and calcium channels. Biochem Biophys Res Commun 270, 370-376.

Jaggar, J.H., Porter, V.A., Lederer, W.J., and Nelson, M.T. (2000). Calcium sparks in smooth muscle. Am J Physiol 278, C235-C256.

Janiak, R., Wilson, S.M., Montague, S., and Hume, J.R. (2001). Heterogeneity of calcium stores and elementary release events in canine pulmonary arterial smooth muscle cells. Am J Physiol 280, C22-C33.

Jha, A., Ahuja, M., Patel, S., Brailoiu, E., and Muallem, S. (2014). Convergent regulation of the lysosomal two-pore channel-2 by $\mathrm{Mg}^{2+}$, NAADP, PI(3,5)P2 and multiple protein kinases. EMBO J 33, 501-511.

Kato, K., Okamura, K., Hatta, M., Morita, H., Kajioka, S., Naito, S., and Yamazaki, J. (2013). Involvement of IP3-receptor activation in endothelin-1-induced $\mathrm{Ca}^{2+}$ influx in rat pulmonary small artery. Eur $\mathbf{J}$ Pharmacol 720, 255-263.

Katz, R.L. (1967). Neuromuscular effects of d-tubocurarine, edrophonium and neostigmine in man. Anesthesiology 28, 327-336.

Kinnear, N.P., Boittin, F.X., Thomas, J.M., Galione, A., and Evans, A.M. (2004). Lysosome-sarcoplasmic reticulum junctions. A trigger zone for calcium signaling by nicotinic acid adenine dinucleotide phosphate and endothelin-1. J Biol Chem 279, 54319-54326.

Kinnear, N.P., Wyatt, C.N., Clark, J.H., Calcraft, P.J., Fleischer, S., Jeyakumar, L.H., Nixon, G.F., and Evans, A.M. (2008). Lysosomes co-localize with ryanodine receptor subtype 3 to form a trigger zone for calcium signalling by NAADP in rat pulmonary arterial smooth muscle. Cell Calcium 44, 190-201.

Kushmerick, M.J., and Podolsky, R.J. (1969). Ionic mobility in muscle cells. Science 166, 1297-1298.

Leblanc, N., Forrest, A.S., Ayon, R.J., Wiwchar, M., Angermann, J.E., Pritchard, H.A., Singer, C.A., Valencik, M.L., Britton, F., and Greenwood, I.A. (2015). Molecular and functional significance of $\mathrm{Ca}^{2+}$-activated $\mathrm{Cl}^{-}$channels in pulmonary arterial smooth muscle. Pulm Circ 5, 244-268.

Lee, C., Chen, D., and Katz, R.L. (1977). Characteristics of nondepolarizing neuromuscular block: (I) post-junctional block by alpha-bungarotoxin. Can Anaesth Soc J 24, 212-219.

Lee, C.H., Poburko, D., Kuo, K.H., Seow, C.Y., and van Breemen, C. (2002). $\mathrm{Ca}^{2+}$ oscillations, gradients, and homeostasis in vascular smooth muscle. Am J Physiol Heart Circ Physiol 282, H1571-1583.

Lee, C.H., Poburko, D., Sahota, P., Sandhu, J., Ruehlmann, D.O., and van Breemen, C. (2001). The mechanism of phenylephrine-mediated $\left[\mathrm{Ca}^{2+}\right](\mathrm{i})$ oscillations underlying tonic contraction in the rabbit inferior vena cava. J Pphysiol 534, 641-650.

Lee, H.C. (2004). Multiplicity of $\mathrm{Ca}^{2+}$ messengers and $\mathrm{Ca}^{2+}$ stores: a perspective from cyclic ADP-ribose and NAADP. Curr Mol Med 4, 227-237.

Lesh, R.E., Nixon, G.F., Fleischer, S., Airey, J.A., Somlyo, A.P., and Somlyo, A.V. (1998). Localization of ryanodine receptors in smooth 
muscle. Circ Res 82, 175-185.

Li, P., and Chen, S.R. (2001). Molecular basis of $\mathrm{Ca}^{2+}$ activation of the mouse cardiac $\mathrm{Ca}^{2+}$ release channel (ryanodine receptor). J Gen Physiol $118,33-44$

Liu, X.R., Zhang, M.F., Yang, N., Liu, Q., Wang, R.X., Cao, Y.N., Yang, X.R., Sham, J.S., and Lin, M.J. (2012). Enhanced store-operated $\mathrm{Ca}^{2+}$ entry and TRPC channel expression in pulmonary arteries of monocrotaline-induced pulmonary hypertensive rats. Am J Physiol 302, C77-87.

Lu, W., Wang, J., Peng, G., Shimoda, L.A., and Sylvester, J.T. (2009). Knockdown of stromal interaction molecule 1 attenuates store-operated $\mathrm{Ca}^{2+}$ entry and $\mathrm{Ca}^{2+}$ responses to acute hypoxia in pulmonary arterial smooth muscle. Am J Physiol Lung Cell Mol Physiol 297, L17-25.

Lu, W., Wang, J., Shimoda, L.A., and Sylvester, J.T. (2008). Differences in STIM1 and TRPC expression in proximal and distal pulmonary arterial smooth muscle are associated with differences in $\mathrm{Ca}^{2+}$ responses to hypoxia. Am J Physiol Lung Cell Mol Physiol 295, L104-L113.

Manunta, M., Rossi, D., Simeoni, I., Butelli, E., Romanin, C., Sorrentino, V., and Schindler, H. (2000). ATP-induced activation of expressed RyR3 at low free calcium. FEBS Lett 471, 256-260.

Marius, P., Guerra, M.T., Nathanson, M.H., Ehrlich, B.E., and Leite, M.F. (2006). Calcium release from ryanodine receptors in the nucleoplasmic reticulum. Cell Calcium 39, 65-73.

McIntyre, R.C., Jr., Banerjee, A., Hahn, A.R., Agrafojo, J., and Fullerton, D.A. (1995). Selective inhibition of cyclic adenosine monophosphate-mediated pulmonary vasodilation by acute hypoxia. Surgery $117,314-318$.

Moore, E.D., Voigt, T., Kobayashi, Y.M., Isenberg, G., Fay, F.S., Gallitelli, M.F., and Franzini-Armstrong, C. (2004). Organization of $\mathrm{Ca}^{2+}$ release units in excitable smooth muscle of the guinea-pig urinary bladder. Biophys J 87, 1836-1847.

Morgan, A.J., and Galione, A. (2008). Investigating cADPR and NAADP in intact and broken cell preparations. Methods 46, 194-203.

Morgan, A.J., and Galione, A. (2014). Two-pore channels (TPCs): current controversies. Bioessays 36, 173-183.

Morio, Y., and McMurtry, I.F. (2002). $\mathrm{Ca}^{2+}$ release from ryanodinesensitive store contributes to mechanism of hypoxic vasoconstriction in rat lungs. J Appl Physiol 92, 527-534.

Navarro-Dorado, J., and Evans, A.M. (2015). Nuclear invaginations demarcate cytoplasmic-nanotubes for integrative calcium signalling to the nucleus. FASEB J 29, Supplement 1, 728.6.

Nazer, M.A., and van Breemen, C. (1998a). Functional linkage of $\mathrm{Na}^{+}-\mathrm{Ca}^{2+}$ exchange and sarcoplasmic reticulum $\mathrm{Ca}^{2+}$ release mediates $\mathrm{Ca}^{2+}$ cycling in vascular smooth muscle. Cell calcium 24, 275-283.

Nazer, M.A., and Van Breemen, C. (1998b). A role for the sarcoplasmic reticulum in $\mathrm{Ca}^{2+}$ extrusion from rabbit inferior vena cava smooth muscle. Am J Physiol 274, H123-131.

Neylon, C.B., Hoyland, J., Mason, W.T., and Irvine, R.F. (1990). Spatial dynamics of intracellular calcium in agonist-stimulated vascular smooth muscle cells. Am J Physiol 259, C675-686.

Neylon, C.B., Richards, S.M., Larsen, M.A., Agrotis, A., and Bobik, A. (1995). Multiple types of ryanodine receptor/ $\mathrm{Ca}^{2+}$ release channels are expressed in vascular smooth muscle. Biochem Biophys Res Commun $215,814-821$.

Ng, L.C., O’Neill, K.G., French, D., Airey, J.A., Singer, C.A., Tian, H., Shen, X.M., and Hume, J.R. (2012). TRPC1 and orai1 interact with STIM1 and mediate capacitative $\mathrm{Ca}^{2+}$ entry caused by acute hypoxia in mouse pulmonary arterial smooth muscle cells. Am J Physiol 303, C1156-1172.

Ogawa, A., Firth, A.L., Smith, K.A., Maliakal, M.V., and Yuan, J.X. (2012). PDGF enhances store-operated $\mathrm{Ca}^{2+}$ entry by upregulating STIM1/Orai1 via activation of Akt/mTOR in human pulmonary arterial smooth muscle cells. Am J Physiol 302, C405-411.

Ogunbayo, O.A., Ma, J., Zhu, M.X., and Evans, A.M. (2015a). LysosomeER coupling supported by two pore channel 2 is required for Nicotinic acid adenine dinucleotide phosphate-induced global calcium waves in pulmonary arterial myocytes. Proc Physiol Soc 34, PC134.

Ogunbayo, O.A., Zhu, Y., Rossi, D., Sorrentino, V., Ma, J., Zhu, M.X., and Evans, A.M. (2011). Cyclic adenosine diphosphate ribose activates ryanodine receptors, whereas NAADP activates two-pore domain channels. J Biol Chem 286, 9136-9140.

Ogunbayo, O.A., Zhu, Y., Shen, B., Agbani, E., Li, J., Ma, J., Zhu, M.X., and Evans, A.M. (2015b). Organelle-specific subunit interactions of the vertebrate two-pore channel family. J Biol Chem 290, 1086-1095.

Panfoli, I., Burlando, B., and Viarengo, A. (1999). Cyclic ADP-ribosedependent $\mathrm{Ca}^{2+}$ release is modulated by free $\left[\mathrm{Ca}^{2+}\right]$ in the scallop sarcoplasmic reticulum. Biochem Biophys Res Commun 257, 57-62.

Pitt, S.J., Funnell, T.M., Sitsapesan, M., Venturi, E., Rietdorf, K., Ruas, M., Ganesan, A., Gosain, R., Churchill, G.C., Zhu, M.X., Parrington, J., Galione, A., and Sitsapesan, R. (2010). TPC2 is a novel NAADPsensitive $\mathrm{Ca}^{2+}$ release channel, operating as a dual sensor of luminal $\mathrm{pH}$ and $\mathrm{Ca}^{2+}$. J Biol Chem 285, 35039-35046.

Poburko, D., Fameli, N., Kuo, K.H., and van Breemen, C. (2008). Ca ${ }^{2+}$ signaling in smooth muscle: TRPC6, NCX and LNats in nanodomains. Channels (Austin) 2, 10-12.

Poburko, D., Liao, C.H., Lemos, V.S., Lin, E., Maruyama, Y., Cole, W.C., and van Breemen, C. (2007). Transient receptor potential channel 6-mediated, localized cytosolic $\left[\mathrm{Na}^{+}\right]$transients drive $\mathrm{Na}^{+} / \mathrm{Ca}^{2+}$ exchanger-mediated $\mathrm{Ca}^{2+}$ entry in purinergically stimulated aorta smooth muscle cells. Circ Res 101, 1030-1038.

Putney, J.W., Jr. (1986). A model for receptor-regulated calcium entry. Cell Calcium 7, 1-12.

Queisser, G., Wiegert, S., and Bading, H. (2011). Structural dynamics of the cell nucleus: basis for morphology modulation of nuclear calcium signaling and gene transcription. Nucleus 2, 98-104.

Ramesh, V., Sharma, V.K., Sheu, S.S., and Franzini-Armstrong, C. (1998). Structural proximity of mitochondria to calcium release units in rat ventricular myocardium may suggest a role in $\mathrm{Ca}^{2+}$ sequestration. Ann N Y Acad Sci 853, 341-344.

Robertson, T.P., Aaronson, P.I., and Ward, J.P. (1995). Hypoxic vasoconstriction and intracellular $\mathrm{Ca}^{2+}$ in pulmonary arteries: evidence for PKC-independent $\mathrm{Ca}^{2+}$ sensitization. Am J Physiol 268, H301-307.

Rosado, J.A., Diez, R., Smani, T., and Jardin, I. (2015). STIM and orai1 variants in store-operated calcium entry. Front Pharmacol 6, 325.

Rosenbluth, J. (1962). Subsurface cisterns and their relationship to the neuronal plasma membrane. J Cell Biol 13, 405-421.

Rowland, A.A., and Voeltz, G.K. (2012). Endoplasmic reticulummitochondria contacts: function of the junction. Nat Rev Mol Cell Biol 13, 607-625

Ruas, M., Davis, L.C., Chen, C.C., Morgan, A.J., Chuang, K.T., Walseth, T.F., Grimm, C., Garnham, C., Powell, T., Platt, N., Platt, F.M., Biel, M., Wahl-Schott, C., Parrington, J., and Galione, A. (2015). Expression of $\mathrm{Ca}^{2+}$-permeable two-pore channels rescues NAADP signalling in TPC-deficient cells. EMBO J 34, 1743-1758.

Ruas, M., Rietdorf, K., Arredouani, A., Davis, L.C., Lloyd-Evans, E., Koegel, H., Funnell, T.M., Morgan, A.J., Ward, J.A., Watanabe, K., Cheng, X., Churchill, G.C., Zhu, M.X., Platt, F.M., Wessel, G.M., Parrington, J., and Galione, A. (2010). Purified TPC isoforms form NAADP receptors with distinct roles for $\mathrm{Ca}^{2+}$ signaling and endolysosomal trafficking. Curr Biol 20, 703-709.

Salvaterra, C.G., and Goldman, W.F. (1993). Acute hypoxia increases cytosolic calcium in cultured pulmonary arterial myocytes. Am J Physiol 264, L323-328.

Schieder, M., Rotzer, K., Bruggemann, A., Biel, M., and Wahl-Schott, C.A. (2010). Characterization of two-pore channel 2 (TPCN2)mediated $\mathrm{Ca}^{2+}$ currents in isolated lysosomes. J Biol Chem 285, 21219-21222.

Shi, J., Miralles, F., Birnbaumer, L., Large, W.A., and Albert, A.P. (2016). Store depletion induces Galphaq-mediated PLCbetal activity to stimulate TRPC1 channels in vascular smooth muscle cells. FASEB J 30, 702-715.

Snetkov, V.A., Knock, G.A., Baxter, L., Thomas, G.D., Ward, J.P., and Aaronson, P.I. (2006). Mechanisms of the prostaglandin F2alphainduced rise in $\left[\mathrm{Ca}^{2+}\right] \mathrm{i}$ in rat intrapulmonary arteries. J Physiol 571, $147-163$.

Soboloff, J., Rothberg, B.S., Madesh, M., and Gill, D.L. (2012). STIM proteins: dynamic calcium signal transducers. Nat Rev Mol Cell Biol $13,549-565$ 
Stevenson, A.S., Gomez, M.F., Hill-Eubanks, D.C., and Nelson, M.T. (2001). NFAT4 movement in native smooth muscle. A role for differential $\mathrm{Ca}^{2+}$ signaling. J Biol Chem 276, 15018-15024.

Subedi, K.P., Paudel, O., and Sham, J.S. (2014). Detection of differentially regulated subsarcolemmal calcium signals activated by vasoactive agonists in rat pulmonary artery smooth muscle cells. Am J Physiol 306, C659-C669.

Takahashi, Y., Watanabe, H., Murakami, M., Ono, K., Munehisa, Y., Koyama, T., Nobori, K., Iijima, T., and Ito, H. (2007). Functional role of stromal interaction molecule 1 (STIM1) in vascular smooth muscle cells. Biochem Biophys Res Commun 361, 934-940.

Takeda, Y., Nystoriak, M.A., Nieves-Cintron, M., Santana, L.F., and Navedo, M.F. (2011). Relationship between $\mathrm{Ca}^{2+}$ sparklets and sarcoplasmic reticulum $\mathrm{Ca}^{2+}$ load and release in rat cerebral arterial smooth muscle. Am J Physiol Heart Circ Physiol 301, H2285-2294.

Tribe, R.M., Borin, M.L., and Blaustein, M.P. (1994). Functionally and spatially distinct $\mathrm{Ca}^{2+}$ stores are revealed in cultured vascular smooth muscle cells. Proc Nat Acad Sci USA 91, 5908-5912.

Tripathy, A., and Meissner, G. (1996). Sarcoplasmic reticulum lumenal $\mathrm{Ca}^{2+}$ has access to cytosolic activation and inactivation sites of skeletal muscle $\mathrm{Ca}^{2+}$ release channel. Biophys J 70, 2600-2615.

Van Breemen, C. (1977). Calcium requirement for activation of intact aortic smooth muscle. J Pphysiol 272, 317-329.

van Breemen, C., Chen, Q., and Laher, I. (1995). Superficial buffer barrier function of smooth muscle sarcoplasmic reticulum. Trends Pharmacol Sci 16, 98-105.

van Breemen, C., Fameli, N., and Evans, A.M. (2013). Pan-junctional sarcoplasmic reticulum in vascular smooth muscle: nanospace $\mathrm{Ca}^{2+}$ transport for site- and function-specific $\mathrm{Ca}^{2+}$ signalling. J Pphysiol 591, 2043-2054.

Verboomen, H., Wuytack, F., De Smedt, H., Himpens, B., and Casteels, R. (1992). Functional difference between SERCA2a and SERCA2b Ca ${ }^{2+}$ pumps and their modulation by phospholamban. Biochem J 286 (Pt 2), 591-595

Wamhoff, B.R., Bowles, D.K., and Owens, G.K. (2006). Excitationtranscription coupling in arterial smooth muscle. Circ Res 98, 868-878.

Wang, X., Zhang, X., Dong, X.P., Samie, M., Li, X., Cheng, X., Goschka, A., Shen, D., Zhou, Y., Harlow, J., Zhu, M.X., Clapham, D.E., Ren, D., and $\mathrm{Xu}, \mathrm{H}$. (2012). TPC proteins are phosphoinositide- activated sodium-selective ion channels in endosomes and lysosomes. Cell 151, 372-383

Waybill, M.M., Yelamarty, R.V., Zhang, Y.L., Scaduto, R.C., Jr., LaNoue, K.F., Hsu, C.J., Smith, B.C., Tillotson, D.L., Yu, F.T., and Cheung, J.Y. (1991). Nuclear calcium gradients in cultured rat hepatocytes. Am J Physiol 261, E49-57.

Weigand, L., Foxson, J., Wang, J., Shimoda, L.A., and Sylvester, J.T. (2005). Inhibition of hypoxic pulmonary vasoconstriction by antagonists of store-operated $\mathrm{Ca}^{2+}$ and nonselective cation channels. Am J Physiol Lung Cell Mol Physiol 289, L5-L13.

Weissmann, N., Dietrich, A., Fuchs, B., Kalwa, H., Ay, M., Dumitrascu,
R., Olschewski, A., Storch, U., Mederos y Schnitzler, M., Ghofrani, H.A., Schermuly, R.T., Pinkenburg, O., Seeger, W., Grimminger, F., and Gudermann, T. (2006). Classical transient receptor potential channel 6 (TRPC6) is essential for hypoxic pulmonary vasoconstriction and alveolar gas exchange. Proc Natl Acad Sci USA 103, 19093-19098.

Williams, D.A., Fogarty, K.E., Tsien, R.Y., and Fay, F.S. (1985). Calcium gradients in single smooth muscle cells revealed by the digital imaging microscope using Fura-2. Nature 318, 558-561.

Wilson, D.P., Sutherland, C., and Walsh, M.P. (2002). $\mathrm{Ca}^{2+}$ activation of smooth muscle contraction: evidence for the involvement of calmodulin that is bound to the triton insoluble fraction even in the absence of $\mathrm{Ca}^{2+}$. J Biol Chem 277, 2186-2192.

Wray, S., and Burdyga, T. (2010). Sarcoplasmic reticulum function in smooth muscle. Physiol Rev 90, 113-178.

Yamaguchi, H., Kajita, J., and Madison, J.M. (1995). Isoproterenol increases peripheral $\left[\mathrm{Ca}^{2+}\right] \mathrm{i}$ and decreases inner $\left[\mathrm{Ca}^{2+}\right] \mathrm{i}$ in single airway smooth muscle cells. Am J Physiol 268, C771-779.

Yamasaki, M., Masgrau, R., Morgan, A.J., Churchill, G.C., Patel, S., Ashcroft, S.J., and Galione, A. (2004). Organelle selection determines agonist-specific $\mathrm{Ca}^{2+}$ signals in pancreatic acinar and beta cells. J Biol Chem 279, 7234-7240.

Yang, D., Pan, Z., Takeshima, H., Wu, C., Nagaraj, R.Y., Ma, J., and Cheng, H. (2001). RyR3 amplifies RyR1-mediated $\mathrm{Ca}^{2+}$-induced $\mathrm{Ca}^{2+}$ release in neonatal mammalian skeletal muscle. J Biol Chem 276, 40210-40214.

Yu, Y., Keller, S.H., Remillard, C.V., Safrina, O., Nicholson, A., Zhang, S.L., Jiang, W., Vangala, N., Landsberg, J.W., Wang, J.Y., Thistlethwaite, P.A., Channick, R.N., Robbins, I.M., Loyd, J.E., Ghofrani, H.A., Grimminger, F., Schermuly, R.T., Cahalan, M.D., Rubin, L.J., and Yuan, J.X. (2009). A functional single-nucleotide polymorphism in the TRPC6 gene promoter associated with idiopathic pulmonary arterial hypertension. Circulation 119, 2313-2322.

Zhang, S., Patel, H.H., Murray, F., Remillard, C.V., Schach, C., Thistlethwaite, P.A., Insel, P.A., and Yuan, J.X. (2007). Pulmonary artery smooth muscle cells from normal subjects and IPAH patients show divergent cAMP-mediated effects on TRPC expression and capacitative $\mathrm{Ca}^{2+}$ entry. Am J Physiol Lung Cell Mol Physiol 292, L1202-L1210.

Zhang, Y., Wang, Y., Yang, K., Tian, L., Fu, X., Wang, Y., Sun, Y., Jiang, Q., Lu, W., and Wang, J. (2014). BMP4 increases the expression of TRPC and basal $\left[\mathrm{Ca}^{2+}\right] \mathrm{i}$ via the p38MAPK and ERK1/2 pathways independent of BMPRII in PASMCs. PLoS One 9, e112695.

Zhu, M.X., Ma, J., Parrington, J., Calcraft, P.J., Galione, A., and Evans, A.M. (2010). Calcium signaling via two-pore channels: local or global, that is the question. Am J Physiol 298, C430-C441.

Zong, X., Schieder, M., Cuny, H., Fenske, S., Gruner, C., Rotzer, K., Griesbeck, O., Harz, H., Biel, M., and Wahl-Schott, C. (2009). The two-pore channel TPCN2 mediates NAADP-dependent $\mathrm{Ca}^{2+}$-release from lysosomal stores. Pflugers Arch 458, 891-899

Open Access This article is distributed under the terms of the Creative Commons Attribution License which permits any use, distribution, and reproduction in any medium, provided the original author(s) and source are credited. 